УДК 621.923.6:621.318.4:621.002.3

\title{
КОНТАКТНА ВЗАЕМОДІЯ АБРАЗИВНОГО ІНСТРУМЕНТУ ТА ПОВЕРХОНЬ ОБРОБЛЕННЯ ДЕТАЛЕЙ ДРУКАРСЬКИХ МАШИН ПРИ СУПЕРФІНІШУВАННІ АБРАЗИВНИМИ БРУСКАМИ
}

( Ю. Ю. Віцюк, к.т.н., Т. А. Роїк, д.т.н., професор, В. Г. Олійник, К.т.н., доцент, А. П. Гавриш, А.т.н., професор, НТУУ «КПІ», Київ, Україна

В статье приведены результаты теоретического исследования взаимодействия абразивного инструмента и поверхностей обработки деталей печатных машин при суперфинишировании абразивными брусками. Созданы математические модели для практических расчетов.

In the article the theoretical research results of interaction the abrasive tools and parts's surfaces for printing machines at superfinishing process by abrasive hones have been presented. The mathematical simulations for practical calculations have been developed.

\section{Постановка проблеми}

Теоретичні аспекти контактної взаємодії тертьових поверхонь, яка обумовлює параметри зносостійкості деталей пар тертя достатньо детально розглянуті у багатьох літературних джерелах [1-18].

Проте, для оцінки міцності деталі тертя офсетної друкарської машини, що піддається високим експлуатаційним навантаженням недостатньо тільки визначення максимального тиску вздовж поверхні контакту. У роботах $[1,2]$ було звернуто увагу на те, що незалежно від форми площі контакту найбільш загрозливий напружений стан виникає не у поверхні контакту, а на деякій глибині під нею. В результаті проведених теоретичних досліджень були отримані формули для розрахунків площ контакту, значень найбільшого тиску між дотичними тілами та їх зближення залежно від форми тіл та іх взаємного розташування. При цьому відзначають чотири площини дотику: номінальну $A_{\alpha}$, контурну $A_{c}$, фактичну $A_{1}$ та фізичну $\mathrm{A}_{\mathrm{f}}$. Процеси зовнішнього тертя, змащувальної дії та зношування значною мірою визначаються геометричними та фізичними властивостями зони контакту твердих тіл [9-17]. Ділянки фактичного контакту не є зонами дійсного контакту [14-17] і на субмікроскопічному рівні мають дискретний характер [7, 14, 15]. Доведено, що фізична (дійсна) площа контакту складає близько 1 \% фактичної площі і в цій області реалізується теоретична міцність матеріалу на поверхні $[6-14,16,17]$.

Фактична площа контакту $€$ функцією стискаючого навантаження й змінюється у широких 
межах залежно від номінальної площі, фізико-механічних властивостей та шорсткості контактуючих поверхонь.

При контактуванні шорсткої поверхні 3 гладкою спочатку вступають у дотик найбільш високі ділянки поверхні, а при подальшому зближенні контактувати починають менш високі виступи.

Зі збільшенням навантажень на пару тертя відбувається пружна та пластична деформації хвиль, на яких розташовані мікронерівності. У кожен момент часу деформація різних виступів однієї поверхні буде різною при певному наближенні. Найбільше деформуються найвищі виступи. При контактуванні менш твердої шорсткої поверхні з більш твердою гладкою виступи шорсткої поверхні у процесі деформування розплющуються. Якщо ж гладка поверхня має меншу твердість, ніж шорстка, то виступи шорсткої поверхні зі зростанням ступеню деформації втискуються у гладку. При цьому при контактуванні двох шорстких поверхонь першими вступають у контакт виступи, сума яких на даний момент виявиться найбільшою.

3 подальшим зростанням навантаження у контакт вступають нові пари протистоячих один до одного виступів, які, в решті решт, мають усе меншу суму висот виступів. Саме така площа дотику буде складатись 3 ділянок, які розташовані на різних висотах і під різними кутами, а фактична площа контакту становитиме незначну долю номінальної [12, 13, 15, 16].
На жаль, означена класична схема взаємодії шорстких поверхонь у повній мірі не віддзеркалює усю складність процесів при контактуванні відносно гладкої та суто абразивної поверхні, якою, наприклад, $є$ ріжуча поверхня абразивного бруска при прецизійній обробці отворів деталей оздоблювальним хонінгуванням та зовнішніх циліндричних поверхонь обертання деталей тертя офсетних друкарських машин надтонким суперфінішуванням. Інформація про такі дослідження у науковотехнічній літературі відсутня. Складність проблеми ще більше посилюється у зв'язку з тим, що для суттєвого підвищення ресурсу поліграфічної техніки в останні роки для вузлів і деталей друкарських машин створені нові високолеговані, важкооброблювані та зносостійкі самозмащувальні композиційні матеріали [18-20].

Прецизійна абразивна обробка нових композитів вивчена ще недостатньо. Наразі кількість публікацій у цьому напрямку налічується одиницями і має по своїй суті здебільшого емпіричний характер [21-25], що не дозволяє прогнозовано та цілеспрямовано обирати режими прецизійної обробки деталей тертя з таких матеріалів для одержання наперед заданих стабільно високих експлуатаційних властивостей.

Тому теоретичне дослідження взаємодії поверхні оброблення нових композитних деталей тертя офсетних друкарських машин з поверхнею абразивного бруску при надтонкій абразивній обробці

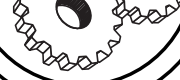

inge

4 
деталей хонінгуванням чи суперфінішуванням, створення відповідних математичних моделей та одержання можливості на цій основі сформулювати механізм та встановити фізичну сутність явищ, які відбуваються у контактній зоні взаємодії абразивного інструменту та деталі $€$ актуальним питанням, що має наукове та, безумовно, практичне значення.

\section{Мета роботи}

Встановлення механізму контактної взаємодії абразивного інструменту та деталей тертя офсетних друкарських машин при надтонкій абразивній обробці шляхом побудови математичних моделей, що описують феноменологічні процеси у зоні їх контакту.

\section{Результати проведених досліджень}

В основу напрацювань авторів даної роботи було покладено загальні положення теорії контактування поверхонь деталей тертя [1-18] та загальні методики теорії абразивного оброблення [26-29].

При контакті шорстких поверхонь абразивного інструменту і деталі найчастіше відбувається контактування шорсткої та хвилеподібної поверхонь. Крім того, внаслідок випадкового розташування абразивних зерен на поверхні інструменту вони можуть розглядатись як додаткова шорсткість.

Для розрахунку контакту поверхонь інструменту та деталі приймаємо такі припущення:

1. Мікронерівності поверхонь моделюються сферичними сег-

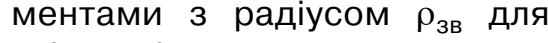
зв'язки інструменту та $\rho_{д}$ для деталі, які мають згідно теорії ймовірності випадкову висоту;

2. Абразивні зерна моделюються сферами з радіусом $\rho_{\alpha}$, а частка зерна, що виступає над поверхнею, підкоряється закону випадкового розподілення;

3. Хвилеподібність поверхонь моделюється сферичними сегментами $з$ радіусом $\mathrm{R}_{\mathrm{i}}$ для

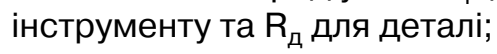

4. Контакт інструменту та деталі вважається статичним, а динаміку процесу оброблення далі необхідно враховувати шляхом застосування коефіцієнту динаміки, який встановлюється експериментально.

Розглянемо випадкову шорстку поверхню.

Визначимо деяку ділянку цієї поверхні з площею $\mathrm{A}_{\mathrm{c}}$, яку визначають контурною площею даної ділянки поверхні. Гладку поверхню, на якій розташовані виступи мікронерівностей, умовно назвемо базовою поверхнею. Проведемо поверхню, яка паралельна базовій і знаходиться від неї на відстані h. Суму площ перерізів мікронерівностей на рівні $\mathrm{h}$ визначимо через $A_{s}$, a максимальну висоту мікронерівностей - через $\mathrm{R}_{\max }$.

Тоді відносне зближення поверхонь підраховується згідно формули:

$$
\varepsilon=\frac{\mathrm{R}_{\max }-\mathrm{h}}{\mathrm{R}_{\max }},
$$

а відносна площа перерізу профілю:

$$
t_{\rho}=\frac{A_{s}}{A_{c}} .
$$


Нехай у - відстань від певної точки шорсткої границі поверхні до базової поверхні. Ймовірність $\mathrm{P}_{\mathrm{r}}$ нерівності $\mathrm{y} \geq \mathrm{h}$ має вигляд:

$$
P_{r}(y \geq h)=t_{p} .
$$

Після введення безрозмірної величини $\Theta=y / R_{\max }$ Отримуємо:

$$
P_{r}(\Theta \geq 1-\varepsilon) \text {. }
$$

Якщо закон розподілення параметрів нормальний, маємо

$$
t_{p}=1-\frac{1}{\sigma \sqrt{2 \pi}} \int_{0}^{1-\varepsilon} e^{-\frac{(\Theta-\bar{\Theta})^{2}}{2 \sigma^{2}} d \Theta}
$$

де $\bar{\Theta}$ та $\sigma-$ математичне очікування та середньоквадратичне відхилення випадкового значення .

Залежність (3) при $0 \leq t_{p} \leq$ $\leq 0,5 \mathrm{~S}_{\mathrm{m}}$ апроксимується ступеневою функцією:

$$
t_{p}=b \varepsilon^{v},
$$

де $\mathrm{S}_{\mathrm{m}}-$ відношення сумарної площі основ мікронерівностей до контурної площі. За відсутності абразивних зерен $\mathrm{S}_{\mathrm{m}}=1 ; \mathrm{b}$ та $v-$ параметри кривої опорної поверхні, які встановлюються за реальними профілограмами. Залежність (4) відповідає закону нормального розподілення i, зокрема, у конкретному випадку $\mathrm{b}=4 \mathrm{i} v=3$.

При $t_{p}>0,5 S_{m}$ крива опорної поверхні апроксимується аналогічною залежністю, але 3 параметрами опорної кривої b' i $v^{\prime}$, які для $0,5 \mathrm{~S}_{\mathrm{m}}<\mathrm{t}_{\mathrm{p}} \leq 0,7 \mathrm{~S}_{\mathrm{m}}$ становлять [11]:

$$
v^{\prime}=2 \operatorname{tg} \beta_{1} \varepsilon_{0,5},
$$

$$
b^{\prime}=\frac{0,5}{\varepsilon_{0,5}^{v^{\prime}}},
$$

де $\beta_{1}-$ кут нахилу опорної кривої у середній частині, тобто при $t_{p}=0,5 ; \varepsilon_{0,5}-$ відносне зближення при $t_{p}=0,5$.

Відносна опорна довжина профілю може бути встановлена до рівня середньої лінії за наступними формулами $[7,12-14,16]$ :

$$
t_{p}=t_{m}\left(\frac{p R_{\max }}{100 R_{m}}\right)\left(\frac{t_{m} R_{m}}{50 R_{a}}-1\right),
$$

нижче рівня середньої лінії:

$$
t_{p}=100-t_{m}\left[\frac{R_{\text {max }}(100-p)}{100\left(R_{\text {max }}-R_{m}\right)}\right]^{\left(\frac{50 R_{2}-t_{m} R_{m}}{50 R_{a}}\right)},
$$

де $t_{m}$ - відносна опорна довжина профілю на рівні середньої лінії, $\mathrm{R}_{\mathrm{m}}-$ відстань між лінією вершин шорсткості та середньою лінією.

Маючи криву опорної поверхні, можна знайти розподіл вершин мікронерівностей за висотою. Позначимо

$$
\begin{gathered}
\varphi(\varepsilon)=\frac{\mathrm{n}_{\mathrm{r}}}{\mathrm{n}_{0}} ; \\
\overline{\psi(\varepsilon)}=\frac{\Delta \overline{\mathrm{A}_{\mathrm{r}}}}{\Delta \overline{\mathrm{Ac}}},
\end{gathered}
$$

де $\mathrm{n}_{\mathrm{r}}$ - число мікронерівностей, висота $x$ яких задовольняє нерівність $1-\frac{\mathrm{x}}{\mathrm{R}_{\mathrm{m}}} \leq \varepsilon ; \mathrm{n}_{0}-$ загальне число мІкровиступів;

$\Delta \overline{\mathrm{Ac}}-$ середня площа перерізу мікронерівностей 3 висотою $\mathrm{x}\left(1-\frac{\mathrm{x}}{\mathrm{R}_{\max }} \leq \varepsilon\right)$ поверхнею, яка від- 
віддалена від базової на відстань $\mathrm{h} ; \Delta \overline{\mathrm{A}}-$ середня площа бази мікронерівності. Має місце рівняння:

$$
\mathrm{t}_{\mathrm{p}}(\varepsilon)=\varphi(\varepsilon) \bar{\psi}(\varepsilon) \mathrm{S}_{\mathrm{m}} .
$$

Функція $\bar{\psi}(\varepsilon)$ може бути представлена у вигляді [16]:

$$
\bar{\psi}(\varepsilon)=\mathrm{k} \varepsilon .
$$

3 формул (4) та визначається

$$
\varphi(\varepsilon)=\frac{\mathrm{b}}{\mathrm{kS}_{\mathrm{m}}} \varepsilon^{\nu-\gamma},
$$

де $\gamma-$ коефіцієнт, що характеризує форму виступів; k - коефіцієнт, який не перевищує одиницю. У випадку сферичного виступу $\mathrm{k}=1 / \mathrm{v}$; $\gamma=1$.

Розглянемо дві шорсткі поверхні, які спочатку знаходились на відстані $R_{\max 1}+R_{\max 2}$, a потім наблизились на величину а. Індекси 1 та 2 позначають першу та другу поверхні. Позначимо

$$
\varepsilon=\frac{\mathrm{a}}{\mathrm{R}_{\max 1}+\mathrm{R}_{\max 2}} .
$$

Нехай $\mathrm{y}_{1}$ та $\mathrm{y}_{2}-$ відстані від протилежних точок цих поверхонь до їх базових поверхонь.

Під $t_{p}$ будемо розуміти наступний вираз:

$$
\mathrm{t}_{\mathrm{p}}=\mathrm{P}_{\mathrm{r}}\left(\frac{\mathrm{y}_{1}+\mathrm{y}_{2}}{\mathrm{R}_{\max 1}+\mathrm{R}_{\max 2}} \geq 1-\varepsilon\right) .(7)
$$

На основі виразів (1) та (4) одержуємо:

$$
\begin{aligned}
& \mathrm{t}_{\mathrm{p}}=\mathrm{P}_{\mathrm{r}}\left(\frac{\mathrm{R}_{\max 1}-\mathrm{y}_{1}}{\mathrm{R}_{\max 1}+\mathrm{R}_{\max 2}}+\frac{\mathrm{R}_{\max 2}-\mathrm{y}_{2}}{\mathrm{R}_{\max 1}+\mathrm{R}_{\max 2}} \leq \varepsilon\right)= \\
& =\int_{0}^{\varepsilon} \frac{P_{r}\left(x \leq \frac{R_{\text {max } 1}-y_{1}}{R_{\max 1}+R_{\max 2}} \leq x+\partial x\right)}{\partial x} x \\
& \times P_{r}\left(\frac{R_{\max 2}-y_{2}}{R_{\max 1}+R_{\max 2}} \leq \varepsilon-x\right) \partial x= \\
& =\int_{0}^{e} b_{1} v_{1}\left(\frac{R_{\max 1}+R_{\max 2}}{R_{\max 1}}\right)^{v_{1}} \times \\
& x x^{v_{1}-1} b_{2}\left(\frac{R_{\max 1}+R_{\max 2}}{R_{\max 2}}\right)^{v_{2}} \times \\
& x(\varepsilon-x)^{v_{2}} \partial x=\frac{b_{1} b_{2} v_{1}}{R_{\max 1}^{v_{1}} R_{\max 2}^{v_{2}}} x \\
& \times\left(R_{\max 1}+R_{\max 2}\right)^{v_{1}+v_{2}} \times \\
& \times B\left(v_{1}, v_{2}\right) \times B\left(v_{1}, v_{2}+1\right) \varepsilon^{v_{1}+v_{2}}= \\
& =\frac{b_{1} b_{2} v_{1} v_{2}}{v_{1}+v_{2}} B\left(v_{1}, v_{2}\right) \times \\
& \times \frac{\left(R_{\max }+R_{\max }\right)^{v_{1}+v_{2}}}{R_{\max }^{v_{1}} R_{\max 2}^{v_{2}}} \varepsilon^{v_{1}+v_{2}},
\end{aligned}
$$

де $\mathrm{B}\left(v_{1}, v_{2}\right)$ - бета-функція.

Позначимо через $\mathrm{A}_{\mathrm{r}}$ фактичну площу контакту шорстких поверхонь, що є сумою площ плям контакту мікронерівностей, при цьому $\mathrm{A}_{r}$ та $t_{p}$ пов'язані між собою наступним рівнянням:

$$
A_{r}=\alpha_{1} t_{p} A_{c},
$$

де $\alpha_{1}-$ коефіцієнт, який визначає стиснення виступів мікронерівностей $\left(0,5 \leq \alpha_{1} \leq 1\right.$, іноді $\alpha>1)$. У випадку пружного контакту $\alpha_{1}=0,5$; у випадку пластичного контакту $\alpha_{1} \sim 1$.

При контактуванні гладкої та шорсткої поверхонь $t_{p}$ у формулі (9) визначається 3 виразу (4), а при контактуванні двох шорстких поверхонь - 3 виразу (8). 
Розглянемо дві шорсткі поверхні, наближені на відстань

$$
\mathrm{a}=\left(\mathrm{R}_{\max 1}+\mathrm{R}_{\max 2}\right) \varepsilon .
$$

Встановимо кількість контактуючих виступів $\mathrm{n}(\varepsilon)$. Для цього замінемо ці поверхні однією еквівалентною, яка має у якості опорної поверхні залежність (8). 3 формул (6) та (8) отримуємо

$$
\varphi(\varepsilon)=\frac{\mathrm{n}(\varepsilon)}{\mathrm{n}_{\mathrm{c}}}=\frac{\mathrm{b}}{\mathrm{kS}_{\mathrm{m}}} \varepsilon^{\nu-\gamma},
$$

де $b=\frac{b_{1} b_{2} v_{1} v_{2}}{v_{1}+v_{2}} \times$

$$
\begin{aligned}
& \times \frac{\left(R_{\max 1}+R_{\max 2}\right)^{v_{1}+v_{2}}}{R_{\max 1}^{v_{1}} R_{\max 2}^{v_{2}}} \\
& \times B\left(v_{1}, v_{2}\right) ;
\end{aligned}
$$$$
v=v_{1}+v_{2} \text {. }
$$

Параметри k і $\gamma$ визначаються формою еквівалентної мікронерівності. Для сферичних виступів $\mathrm{k}=\frac{1}{v_{1}+v_{2}}, \gamma=1$.

При взаємодії мікронерівностей деталі та абразивного інструменту у вигляді бруску контакт між ними може бути пружним, пластичним та пружно-пластичним.

При пружному контакті розрахунок ведеться за відомою формулою Герца [1]:

$$
\mathrm{N}_{\mathrm{i}}=\frac{4}{3 \mathrm{I}} \rho^{1 / 2} \mathrm{a}_{\mathrm{i}}^{3 / 2},
$$

де $\mathrm{N}_{\mathrm{i}}$ - сила стискання пари мікронерівностей; $\alpha_{i}-$ зближення.

$$
I=\frac{1-\mu_{1}^{2}}{E_{1}}+\frac{1-\mu_{2}^{2}}{E_{2}},
$$

де $\mathrm{E}_{1}, \mathrm{E}_{2}, \mu_{1}$ та $\mu_{2}-$ відповідно модулі пружності та коефіцієнти Пуассона інструменту та деталі;

$$
\rho=\frac{\rho_{1} \rho_{2}}{\rho_{1}+\rho_{2}},
$$

де $\rho_{1}$ та $\rho_{2}-$ радіуси вершин мікронерівностей інструменту та деталі.

При пластичному контакті без зміцнення має місце рівняння:

$$
\mathrm{N}_{\mathrm{i}}=\mathrm{c} \sigma_{\mathrm{T}} \Delta \mathrm{A}_{\mathrm{r}},
$$

де $\sigma_{\mathrm{T}}$ - межа плинності; с - коефіцієнт стиснення (с 3); $\Delta \mathrm{A}_{r}-$ площа контакту мікронерівностей.

3 геометричних міркувань робимо висновок, що для пари сферичних мікронерівностей

$$
\Delta \mathrm{A}_{\mathrm{r}}=2 \pi \alpha_{1} \rho \mathrm{a}_{\mathrm{i}},
$$

де $\alpha \sim 1$.

Підставляючи вираз (13) в (12), отримуємо:

$$
\mathrm{N}_{\mathrm{i}}=2 \pi \alpha_{1} c \sigma_{T} \rho a_{\mathrm{i}}
$$

У випадку пластичного контакту зі зміцненням скористуємось формулою Майера [1, 6] для контакту двох сфер:

$$
\mathrm{N}_{\mathrm{i}}=\mathrm{gd}^{\mathrm{n}} \text {, }
$$

де $\mathrm{d}$ - діаметр (умовний) відбитку при втискуванні жорсткої сфери у напівпростір; g та $\mathrm{n}$ - відповідно екстрапольована межа плинності та коефіцієнт, що характеризує здатність матеріалу оброблення до зміцнення.

3 геометричних уявлень слідує, що

$$
d \approx\left(8 a_{i} \rho\right)^{1 / 2} .
$$

Таким чином

$$
N_{i}=g(8 \rho)^{n / 2} a_{i}^{n / 2} \text {. }
$$


В загальному вигляді зв'язок між навантаженням та зближенням поверхонь контакту може бути записаний у такому вигляді:

$$
\mathrm{N}_{\mathrm{i}}=\mathrm{Fa}_{\mathrm{i}}^{\lambda} .
$$

Свої особливості має також і контактування мікронерівностей деталі оброблення та зв'язки абразивного інструменту при суперфінішуванні чи хонінгуванні.

Уявімо, що відбувався перший дотик інструменту і деталі. Приймемо такі позначення: $\mathrm{H}_{\max }$ - найбільший виступ абразивного зерна над базовою поверхнею зв'язки; $\mathrm{R}_{\max 1-}$ найбільша висота мікронерівностей зв'язки абразивного бруску (інструменту); $\mathrm{R}_{\max 2-}$ найбільша висота мікронерівностей деталі, що оброблюється. У цей момент відстань між базовими поверхнями деталі та інструменту дорівнюе $\mathrm{H}_{\max }+$ $+R_{\max 2}$. Нехай далі базові поверхні деталі та інструменту ще більше наблизились одна до одної на величину а.

Тоді величина наближення базових поверхонь деталі та абразивного інструменту, починаючи з моменту першого дотику мікронерівностей деталі та зв'язки інструменту, становить:

$$
\mathrm{a}_{1}=\mathrm{a}-\mathrm{H}_{\max }+\mathrm{R}_{\max 1} .
$$

Приймемо, що $\mathrm{h}=\mathrm{R}_{\max 1}+$ $+\mathrm{R}_{\max 2}-\mathrm{h}_{1}-\mathrm{h}_{2}$,

де $\mathrm{h}_{1}$ та $\mathrm{h}_{2}$ - висота двох контактуючих мікронерівностей зв'язки інструменту та деталі.

Зближення цих виступів після їх контакту дорівнює $\mathrm{a}_{1}-\mathrm{h}$.
3 формули (18) слідує, що діюча на ці виступи сила складає:

$$
\mathrm{dP}_{3 \mathrm{~B}}=\mathrm{F}\left(\mathrm{a}_{1}-\mathrm{h}\right)^{\lambda} .
$$

3 виразу (10) витікає, що число виступів, для яких $\mathrm{x} \leq \mathrm{h} \leq$ $\leq \mathrm{x}+\mathrm{dx}$, дорівнює:

$$
\begin{aligned}
& \mathrm{dN}_{3 \mathrm{~B}}(\mathrm{x})= \\
& =\frac{\mathrm{n}_{3 \mathrm{~B}} \mathrm{~b}(\nu-\gamma) \mathrm{x}^{v-\gamma-1}}{\left(1-\mathrm{S}_{\mathrm{a}}\right) \mathrm{k}\left(\mathrm{R}_{\max 1}+\mathrm{R}_{\max 2}\right)^{v-\gamma}} \mathrm{dx},
\end{aligned}
$$

де $\mathrm{S}_{\mathrm{a}}$ - відношення сумарної площі бази абразивних зерен, тобто перерізів їх базовою поверхнею до контурної площі, яка встановлюється експериментально з профілограм.

Число $\mathrm{n}_{\text {зв }}$ пропорційне контурній площі $\mathrm{A}_{\mathrm{c}}$ :

$$
\mathrm{n}_{3 \mathrm{~B}}=\mathrm{GA}_{\mathrm{c}}
$$

де $\mathrm{G}$ - коефіцієнт пропорційності, що встановлюється експериментально.

Сумарна сила, що діє між мікронерівностями деталі i зв'язки інструменту:

$$
\begin{aligned}
& P_{3 в}=\int_{0}^{a_{1}} F\left(a_{1}-x\right)^{\lambda} G A_{c} \times \\
& \times \frac{b(v-\gamma) x^{v-\gamma-1}}{\left(1-S_{a}\right) k\left(R_{\max 1}+R_{\max 2}\right)^{v-\gamma}} d x= \\
& =\frac{F G A_{c} b(v-\gamma)}{\left(1-S_{a}\right) k\left(R_{\max 1}+R_{\max 2}\right)^{v-\gamma}} \times \\
& \times B(\lambda+1, v-\gamma) a_{1}^{\lambda+v-\gamma} .
\end{aligned}
$$

Сумарна фактична площа контакту між нерівностями деталі та зв'язки інструменту на основі (8) та (9) становить:

$$
A_{\text {rзв }}=\frac{\alpha_{1} b a_{1}^{v}}{\left(R_{\max 1}+R_{\max 2}\right)^{v}} A_{c} .
$$


Кількість контактуючих мікронерівностей $\mathrm{N}_{3 в}$ деталі та зв'язки абразивного інструменту (наприклад, суперфінішного бруску) може бути підрахована на базі формул (10) та (21) і становить:

$$
\mathrm{N}_{3 \mathrm{~B}}=\frac{\mathrm{GA}_{\mathrm{c}} \mathrm{ba}_{1}{ }^{\nu-\gamma}}{\left(1-\mathrm{S}_{\mathrm{a}}\right) \mathrm{k}\left(\mathrm{R}_{\max 1}+\mathrm{R}_{\max 2}\right)^{v-\gamma}} .
$$

Проаналізуємо процес пружно-пластичного контактування абразивних зерен суперфінішного (хонінгувального) бруску з деталлю тертя друкарської машини, що обробляється. Позначимо $\mathrm{a}_{\mathrm{z}}=\mathrm{a}-\mathrm{R}_{\max 2}$. Нехай будь-яке випадкове абразивне зерно виступає над поверхнею інструменту і має висоту $\mathrm{h}_{\mathrm{a}}$. Позначимо силу, що діє під час процесу зрізання з поверхні деталі стружки, через $\mathrm{dP}_{\mathrm{a}}^{\prime}$, зближення абразивного зерна з базовою поверхнею деталі після початку їх контактування - через $\mathrm{f}\left(\mathrm{dP}_{\mathrm{a}}^{\prime}\right)$, а переміщення абразивного зерна у зв'язці - через $\mathrm{f}_{2}\left(\mathrm{dP}_{\mathrm{a}}^{\prime}, \mathrm{h}_{\mathrm{a}}\right)$.

3 геометричних міркувань виходить рівняння:

$$
\begin{aligned}
& \mathrm{a}_{2}-\left(\mathrm{H}_{\max }-\mathrm{h}_{\mathrm{a}}\right)= \\
& =\mathrm{f}_{1}\left(d P_{\mathrm{a}}^{\prime}\right)+\mathrm{f}_{2}\left(d P_{\mathrm{a}}^{\prime}, \mathrm{h}_{\mathrm{a}}\right) .
\end{aligned}
$$

На основі виразу (18)

$$
\begin{aligned}
& \mathrm{f}_{1}\left(\mathrm{dP}_{\mathrm{a}}^{\prime}\right)= \\
& =\mathrm{F}_{a}^{-\frac{1}{\lambda_{\mathrm{a}}}}\left(\mathrm{dP}_{\mathrm{a}}^{\prime}\right)^{1 / \lambda_{\mathrm{a}}},
\end{aligned}
$$

де $\mathrm{F}_{\alpha}$ та $\lambda_{\alpha}-$ коефіцієнти, які встановлені для контакту тіла 3 плоскою основою (сфера 3 нескінченним радіусом) та сфера радіуса $\rho_{\alpha}$.
Функцію $\mathrm{f}_{2}\left(\mathrm{dP}_{\mathrm{a}}^{\prime}, \mathrm{h}_{\mathrm{a}}\right)$ приблизно замінемо виразом $\mathrm{f}_{2}\left(\mathrm{dP}_{\mathrm{a}}^{\prime}, \mathrm{h}_{\mathrm{a}}^{\mathrm{cp}}\right)$, де $h_{a}^{c p}-$ середнє значення $h_{\alpha}$.

Функція $\mathrm{f}_{2}\left(\mathrm{dP}_{\mathrm{a}}^{\prime}, \mathrm{h}_{\mathrm{a}}^{\mathrm{cp}}\right)$, визначається експериментально. Ця функція являє собою залежність:

$$
a_{\text {yп }}=f\left(d P_{a}^{\prime}, \rho_{a}, B^{\prime}\right),
$$

де $\mathrm{a}_{\text {уп }}$ - пружнє переміщення абразивного зерна у зв'язці інструменту; В' - коефіцієнт, який визначається властивостями матеріалу, що оброблюється і який має розмірність напружень (у випадку лінійної залежності він дорівнює модулю пружності, тобто В' = E).

Для встановлення типу цієї залежності доцільним є використання методу тотожності i розмірності у механіці [1]. Виходячи з цього та згідно П-теореми [1] отримуємо:

$$
\mathrm{a}_{\mathrm{yп}}=\mathrm{K}^{\prime}\left(\mathrm{dP}_{\mathrm{a}}^{\prime}\right)^{\mathrm{a}^{\prime}} \rho_{\mathrm{a}}^{\beta^{\prime}} \mathrm{B}^{\prime},
$$

де К' - деяка константа.

Розмірності величин, які входять у ступеневу комбінацію, наступні:

$$
\begin{gathered}
\mathrm{dP}_{\mathrm{a}}=\left[\mathrm{L}_{1} \mathrm{M}_{1} \mathrm{~T}_{1}^{-2}\right] ; \rho_{\mathrm{a}}=\left[\mathrm{L}_{1}\right] ; \\
\mathrm{B}^{\prime}=\left[\mathrm{L}_{1}^{-1} \mathrm{M}_{1} \mathrm{~T}_{1}^{-2}\right] ; \quad \mathrm{a}_{\text {уп }}=\left[\mathrm{L}_{1}\right] .
\end{gathered}
$$

$$
\text { Отже, } \begin{aligned}
& {\left[\mathrm{L}_{1}\right]=\left[\mathrm{L}_{1} \mathrm{M}_{1} \mathrm{~T}_{1}^{-2}\right]^{\alpha} \times } \\
& \times\left[\mathrm{L}_{1}\right]^{\beta}\left[\mathrm{L}_{1}^{-1} \mathrm{M}_{1} \mathrm{~T}_{1}^{-2}\right]^{\gamma^{\prime}} \\
& {\left[\mathrm{L}_{1}\right]=\mathrm{L}_{1}^{\mathrm{a}^{\prime}+\beta^{\prime}-\gamma^{\prime}} \times } \\
& \times \mathrm{M}^{\mathrm{a}^{\prime}+\gamma^{\prime}} \mathrm{T}^{-2 \mathrm{a}^{\prime}-2 \gamma^{\prime}},
\end{aligned}
$$

Звідси $\alpha^{\prime}+\beta^{\prime}-\gamma^{\prime}=1 ; \alpha^{\prime}+\gamma^{\prime}=$ $=0 ;-2 \alpha^{\prime}-2 \gamma^{\prime}=0$. 
Прийнявши $\alpha^{\prime}=\lambda^{\prime}$, отримуємо $\beta^{\prime}=1-2 \lambda^{\prime}$ та $\gamma^{\prime}=-\lambda^{\prime}$.

Таким чином,

або

$$
a_{\text {yп }}=K^{\prime} \frac{\left(d P_{a}^{\prime}\right)^{\lambda^{\prime}}}{B^{\lambda^{\prime}}} \rho_{a}^{1-2 \lambda^{\prime}},
$$

$$
\begin{aligned}
& a_{\text {yn }}=K^{\prime} \rho_{a}\left(\frac{d P_{a}^{\prime}}{B^{\prime} \rho_{a}^{2}}\right)^{\lambda^{\prime}}= \\
& =K^{\prime \prime} \rho_{a}\left(\frac{d P_{a}^{\prime}}{\rho_{a}^{2}}\right)^{\lambda^{\prime}} .
\end{aligned}
$$

Константи К" і $\lambda$ ' встановлюються експериментально.

Праву частину формули (26) будемо апроксимувати ступеневою функцією. Тоді отримуємо:

$$
a_{2}-z_{a}=D_{a}^{-\frac{1}{\mu_{a}}}\left(d P_{a}^{\prime}\right)^{\frac{1}{\mu_{a}}}
$$

де $D_{\mathrm{a}}$ та $\mu_{\mathrm{a}}$ - константи;

$$
\mathrm{z}_{\mathrm{a}}=\mathrm{H}_{\max }-\mathrm{h}_{\mathrm{a}} \text {. }
$$

3 виразу (28) слідує:

$$
\mathrm{dP}_{\mathrm{a}}^{\prime}=\mathrm{D}_{\mathrm{a}}\left(\mathrm{a}_{2}-\mathrm{z}_{\mathrm{a}}\right)^{\mu_{\mathrm{a}}} \text {. }
$$

Для дослідження процесу контактування абразивних зерен з деталлю необхідно мати криву опорної поверхні тієї частини зерен, що виступає над нею. Ця крива будується за відповідними профілограмами і може мати такий вигляд:

$$
t_{\mathrm{pa}}=\mathrm{b}_{\mathrm{a}}\left(\frac{\mathrm{a}_{\mathrm{a}}}{\mathrm{H}_{\max }}\right)^{v_{\mathrm{a}}},
$$

де $\mathrm{a}_{\mathrm{a}}=\mathrm{H}_{\max }-\mathrm{x}_{\mathrm{a}} ; \mathrm{x}_{\mathrm{a}}-$ відстань від базової поверхні інструменту.

Аналогічно з контактуванням мікронерівностей можна одержати такий вираз для загальної кількості абразивних (ріжучих) зерен, які приймають безпосередню участь у пружно-пластич- ному контактуванні (процесі різання):

$$
\mathrm{N}_{\text {уп.пл }}=\mathrm{n}_{\mathrm{a}} \frac{\mathrm{b}_{\mathrm{a}}}{\mathrm{S}_{\mathrm{a}} \mathrm{k}_{\mathrm{a}}^{\prime}}\left(\frac{\mathrm{a}_{2}}{\mathrm{H}_{\max }}\right)^{\mathrm{v}_{\mathrm{a}}-\gamma_{\mathrm{a}}} \text {, }
$$

де $\mathrm{n}_{\mathrm{a}}$ - число абразивних зерен на контурній площі; k' та $\gamma_{\alpha}-$ коефіцієнти, які визначаються формою зерна.

Для сферичної моделі зерен $\mathrm{k}_{\mathrm{a}}^{\prime}=\frac{1}{v_{\mathrm{a}}} ; \quad \gamma_{\mathrm{a}}=1$. Зв'язок між $\mathrm{n}_{\alpha} \mathrm{i}$ $A_{c}$ визначається рівнянням:

$$
\mathrm{n}_{\mathrm{a}}=\mathrm{G}_{\mathrm{a}} \mathrm{A}_{\mathrm{c}},
$$

де $\mathrm{G}_{\mathrm{a}}$ - коефіцієнт пропорційності, який встановлюється експериментально.

Підрахуємо силу $\mathrm{P}_{\mathrm{a}}^{\prime}$, що діє на працюючі абразивні зерна. Розглянемо зерна, для яких $\mathrm{x} \leq \mathrm{Z}_{\mathrm{a}} \leq$ $\leq \mathrm{x}+\mathrm{dx}$. 3 формул (31) та (32) слідує, що число їх дорівнює :

$$
\begin{aligned}
\mathrm{dN}_{\text {уп.пл }}(\mathrm{x}) & =\frac{\mathrm{G}_{\mathrm{a}} \mathrm{A}_{\mathrm{c}}\left(v_{\mathrm{a}}-\gamma_{\mathrm{a}}\right) \mathrm{b}_{\mathrm{a}}}{\mathrm{H}_{\max } \mathrm{k}_{\mathrm{a}}^{\prime} \mathrm{S}_{\mathrm{a}}} \times \\
& \times\left(\frac{\mathrm{x}}{\mathrm{H}_{\max }}\right)^{v_{\mathrm{a}}-\gamma_{\mathrm{a}}-1} \mathrm{dx} .
\end{aligned}
$$

Сила, що діє на зерно,

$$
\mathrm{dP}_{\mathrm{a}}^{\prime}(\mathrm{x})=\mathrm{D}_{\mathrm{a}}\left(\mathrm{a}_{2}-\mathrm{x}\right)^{\mu_{\mathrm{a}}} \text {. }
$$

Отже,

$$
\begin{aligned}
& P_{a}^{\prime}=\int_{0}^{a_{2}} D_{a}\left(a_{2}-x\right)^{\mu_{a}} \times \\
& \times \frac{G_{a} A_{c}\left(v_{a}-\gamma_{a}\right) b_{a}}{H_{m a x} k_{a}^{\prime} S_{a}} \times \\
& \times\left(\frac{x}{H_{\max }}\right)^{v_{a}-\gamma_{a}-1} d x= \\
& =\frac{D_{a} G_{a} A_{c}\left(v_{a}-\gamma_{a}\right) b_{a}}{H_{m a x}^{v_{a}-\gamma_{a}} k_{a}^{\prime} S_{a}} \times \\
& \times B\left(\mu_{a}+1, v_{a}-\gamma_{a}\right) a_{2}^{\mu_{a}+v_{a}-\gamma_{a}} .
\end{aligned}
$$


Візьмемо довільне зерно, для якого $\mathrm{x} \leq \mathrm{Z}_{\mathrm{a}} \leq \mathrm{x}+\mathrm{dx}$. Площа $\mathrm{dA}_{\mathrm{a}}^{\prime}(\mathrm{x})$ його контакту з базовою поверхнею деталі може бути представлена у вигляді

$$
\begin{aligned}
& d A_{a}^{\prime}(x)= \\
& =\pi \alpha_{a}\left[\begin{array}{l}
2 \rho_{a} f_{1}\left(d P_{a}^{\prime}\right)- \\
-f_{1}^{2}\left(d P_{a}^{\prime}\right)
\end{array}\right],
\end{aligned}
$$

де $\alpha_{\mathrm{a}} \sim 1$ і має той самий сенс, що і $\alpha_{1} ; \mathrm{f}_{1}\left(\mathrm{dP}_{\mathrm{a}}^{\prime}\right)$ визначається формулою (27).

Використовуючи формули (27), (29) та (33), можна легко знайти сумарну площу контакту абразивних зерен, що пружнопластично контактують 3 базовою поверхнею деталі оброблення:

$$
\begin{aligned}
& A_{0}^{\prime}=\pi \alpha_{a} \int_{0}^{a_{2}}\left[\begin{array}{l}
2 \rho_{a} F_{a}^{-\frac{1}{\lambda_{a}}} D_{a}^{\frac{1}{\lambda_{a}}}\left(a_{2}-x\right)^{\mu_{a} / \lambda_{a}}- \\
-F_{a}^{-2 / \lambda_{a}} D_{a}^{2 / \lambda_{a}}\left(a_{2}-x\right)^{\mu_{a} / \lambda_{a}}
\end{array}\right] \\
& \times \frac{G_{a} A_{c}\left(v_{a}-\gamma_{a}\right) b_{a}}{H_{m a x} k_{a}^{\prime} S_{a}}\left(\frac{x}{H_{\max }}\right)^{v_{a}-\gamma_{a}-1} d x= \\
& =\frac{\pi \alpha_{a} G_{a} A_{c}\left(v_{a}-\gamma_{a}\right) b_{a} a_{2}^{\mu_{a} / \lambda_{a}+v_{a}-\gamma_{a}}}{H_{m a x}^{v_{a}-\gamma_{a}} k_{a}^{\prime} S_{a}} \times \\
& \times\left(\frac{D_{a}}{F_{a}}\right)^{1 / \lambda_{a}} \times \\
& \left.\times\left[\begin{array}{l}
2 \rho_{a} B\left(\frac{\mu_{a}}{\lambda_{a}}+1, v_{a}-\gamma_{a}\right)- \\
-\left(\frac{D_{a}}{F_{a}}\right)^{1 / \lambda_{a}} a_{2}^{\mu_{a} / \lambda_{a}} B\left(\frac{2 \mu_{a}}{\lambda_{a}}+1, v_{a}-\gamma_{a}\right.
\end{array}\right)\right] .
\end{aligned}
$$

3 формул (31) та (32) слідує, що кількість пружно-пластично контактуючих ріжучих абразивних зерен $\mathrm{N}_{\text {уп.пл }}$, можливо надати у вигляді

$\mathrm{N}_{\text {уп.пл }}=\frac{\mathrm{G}_{\mathrm{a}} \mathrm{A}_{\mathrm{c}} \mathrm{b}_{\mathrm{a}}}{\mathrm{b}_{\mathrm{a}}}\left(\frac{\mathrm{a}_{2}}{\mathrm{H}_{\max }}\right)^{\mu_{\mathrm{a}}+v_{\mathrm{a}}-\gamma_{\mathrm{a}}}$
При розгляді питання пружного контактування абразивних зерен з деталлю набуває важливого значення прискіпливий аналіз явищ, які супроводжують процеси надтонкого абразивного оброблення прецизійних поверхонь деталей тертя.

Позначимо через $\mathrm{dP}_{\mathrm{a}}$ силу взаємодії абразивного зерна та мікронерівності поверхні деталі, а їх взаємне зближення після початкового дотику - через $\mathrm{f}_{1}^{\prime}\left(\mathrm{dP}_{\mathrm{a}}^{\prime \prime}\right)$. Переміщення зерна у зв'язці приймемо рівним $f_{2}\left(d_{a}^{\prime \prime}, h_{a}^{c p}\right)$. 3 геометричних міркувань слідує:

$$
\begin{aligned}
& a-z=f_{1}^{\prime}\left(d P_{a}^{\prime \prime}\right)+ \\
& +f_{2}\left(d P_{a}^{\prime \prime}, h_{a}^{c p}\right),
\end{aligned}
$$

де $\mathrm{z}=\mathrm{H}_{\max }+\mathrm{R}_{\max 2}-\mathrm{h}_{\mathrm{a}}-\mathrm{h}_{2}$; $\mathrm{h}_{\mathrm{a}}, \mathrm{h}_{2}$ - висота виступаючої частини зерна і мікронерівності деталі до деформації.

Функція $\mathrm{f}_{1}^{\prime}\left(\mathrm{dP}_{\mathrm{a}}\right)$ визначається за формулою, аналогічній формулі (27), згідно якої константи $\mathrm{F}_{0}, \lambda_{0}$ встановлюють за методикою для контакту сфер 3 радіусами $\rho_{\text {д }}$ та $\rho_{\mathrm{a}}$ :

$$
f_{1}^{\prime}\left(d P_{a}^{\prime \prime}\right)=F_{0}^{-1 / \lambda_{0}}\left(d P_{a}^{\prime \prime}\right)^{1 / \lambda_{0}} \text {. }
$$

Апроксимуючи праву частину виразу (39) ступеневою функцією, отримуємо аналогічно формулі (29) наступну залежність:

$$
\mathrm{dP}_{\mathrm{a}}^{\prime \prime}=\mathrm{D}_{\mathrm{a}}^{\prime}(\mathrm{a}-\mathrm{z})^{\mu_{\varepsilon}^{\prime}}
$$

Для подальшого аналізу необхідно мати криву опорної поверхні для деталі, яка справедлива при $0,5 \leq t_{p} \leq 0,7$. 
Аналогічно (4), цю криву можливо описати ступеневою залежністю:

$$
t_{p}=b^{\prime} \varepsilon^{v^{\prime}}
$$

Маючи криві опорних поверхонь деталі та абразивних зерен інструменту, можна надати вираз для еквівалентної їм однієї кривої опорної поверхні, аналогічно формулі (8):

$$
t_{p}=b_{0} \varepsilon^{v_{0}}
$$

де

$$
\begin{gathered}
b_{0}=\frac{b_{a} b^{\prime} v_{a} v^{\prime}}{v_{a}+v_{1}} \times \frac{B\left(v_{a} v^{\prime}\right)}{R_{\max _{2}}^{v^{\prime}} H_{\max }^{v_{a}}} \times \\
\times\left(H_{\max }+R_{\max _{2}}\right)^{v_{0}}, \\
v_{0}=v^{\prime}+v_{a} \\
\varepsilon=\frac{a}{H_{\max }+R_{\text {max }_{2}}} .
\end{gathered}
$$

Для пружно-контактуючих абразивних зерен інструменту, які у даний момент не приймають участь у процесі різання металу, має місце така приблизна математична модель:

$$
\begin{aligned}
& \mathrm{h}_{\mathrm{a}}+\mathrm{h}_{2} \leq \mathrm{H}_{\max }+ \\
& +\mathrm{R}_{\text {max }_{2}}-\mathrm{a}+\mathrm{h}_{2}^{\mathrm{cp}},
\end{aligned}
$$

де $h_{2}^{\text {cp }}$ - середнє значення висот мікронерівностей деталі.

3 формули (44) слідує, що для пружно контактуючих абразивних зерен та мікронерівностей деталі має місце нерівність:

$$
\mathrm{a}-\mathrm{h}_{2}^{\mathrm{cp}} \leq \mathrm{z} \leq \mathrm{a} .
$$

Підрахуємо кількість $\mathrm{dN}_{\text {уп }}(\mathrm{x})$ пружно контактуючих зерен та мікронерівностей деталі при $\mathrm{x} \leq \mathrm{z} \leq \mathrm{x}+\mathrm{dx}$. Аналогічно викладеному вище маємо:

$$
\begin{aligned}
& \mathrm{dN}_{\mathrm{y \Pi}}(\mathrm{x})= \\
& =\frac{\left(v_{0}-\gamma_{0}\right) \mathrm{N}_{\mathrm{a}} \mathrm{b}_{0} \mathrm{x}^{v_{0}-\gamma_{0}-1}}{\mathrm{k}_{0} \mathrm{~S}_{\mathrm{a}}\left(\mathrm{H}_{\max }+\mathrm{R}_{\text {max }_{2}}\right)^{v_{0}-\gamma_{0}}} \mathrm{dx},
\end{aligned}
$$

де $\mathrm{N}_{\mathrm{a}}$ - загальна кількість виступів вершин еквівалентній поверхні.

\section{Для сферичних виступів} $\mathrm{k}_{0}=\frac{1}{v_{0}} ; \quad \gamma_{0}=1 . \quad$ Між $\mathrm{N}_{\mathrm{a}}^{\prime}$ та $\mathrm{A}_{\mathrm{c}}$ існує зв' язок

$$
\mathrm{N}_{\mathrm{a}}^{\prime}=\mathrm{G}_{\mathrm{a}}^{\prime} \mathrm{A}_{\mathrm{c}}
$$

де $\mathrm{G}_{\mathrm{a}}^{\prime}$ - коефіцієнт пропорційності, який встановлюють експериментально.

Розрахуємо силу $\mathrm{P}_{\text {a }}$ взаємодії між абразивними зернами та мікронерівностями деталі при пружному контакті:

$$
\begin{aligned}
& P_{a}^{\prime \prime}=\int_{a-h_{2}^{c p}}^{a} D_{a}^{\prime}(a-x)^{\mu_{a}^{\prime}} \times \\
& \times \frac{G_{a}^{\prime} A{ }_{c} b_{0}\left(v_{0}-\gamma_{0}\right) x^{v_{0}-\gamma_{0}-1}}{S_{a} k_{0}\left(H_{\max }+R_{\max _{2}}\right)^{v_{0}-\gamma_{0}}} d x= \\
& =\frac{D_{a}^{\prime} G_{a}^{\prime} A_{c} b_{0}\left(v_{0}-\gamma_{0}\right)}{S_{a} k_{0}\left(H_{\max }+R_{\max _{2}}\right)^{v_{0}-\gamma_{0}}} \times \\
& \times a^{\mu_{a}^{\prime}+v_{0}-\gamma_{0}} \int_{1-\frac{n_{2}^{c p}}{a}}^{1}(1-x)_{0}^{\mu_{a}^{\prime}} x^{v_{0}-\gamma_{0}-1} d x .
\end{aligned}
$$

Далі

$$
\int_{1-\frac{h_{2}^{c p}}{a}}^{1}(1-x)^{\mu_{a}^{\prime}} x^{v_{0}-y_{0}-1} d x \approx
$$




$$
\begin{aligned}
& \approx\left(1-\frac{h_{2}^{c p}}{2 a}\right)^{v_{0}-\gamma_{0}-1} \times \\
& \times\left(\frac{h_{2}^{c p}}{a}\right)^{\mu_{a}^{\prime}+1} \times \frac{1}{\mu_{a}^{\prime}+1} .
\end{aligned}
$$

Отже,

$P_{a}^{\prime \prime}=\frac{D_{a}^{\prime} G_{a}^{\prime} A_{c} b_{0}\left(v_{0}-\gamma_{0}\right)}{S_{a} k_{0}\left(H_{\text {max }}+R_{\text {max }_{2}}\right)^{v_{0}-\gamma_{0}}\left(\mu_{a}^{\prime}+1\right)} \times$

$\times\left(\mathrm{a}-\frac{\mathrm{h}_{2}^{\mathrm{cp}}}{2}\right)^{\mathrm{v}_{0}-\gamma_{0}}-1 \times\left(\mathrm{h}_{2}^{\mathrm{cp}}\right)^{\mu_{\mathrm{a}+1}^{\prime}}$.

Позначимо черезdА"площу контакту між мікронерівністю деталі та зерном:

$$
\begin{aligned}
& d A_{a}^{\prime \prime}=2 \pi \alpha_{a}^{\prime} f_{1}^{\prime}\left(d P_{a}^{\prime \prime}\right) \times \\
& \times \frac{\rho_{д} \rho_{a}}{\rho_{д}+\rho_{a}},
\end{aligned}
$$

де $\mathrm{f}_{1}^{\prime}\left(\mathrm{dP}_{\mathrm{a}}\right)$ визначається за формулою (40); $\alpha_{a}^{\prime} \approx 1$ має той же сенс, що і $\mathrm{a}_{\mathrm{a}}$.

На основі формул (46) та (51) отримуємо вираз для площі пружного контакту між мікронерівностями деталі та зернами:

$$
\begin{aligned}
& A_{a}^{\prime \prime}=\frac{2 \pi \alpha_{a}^{\prime} \rho_{д} \rho_{a}}{\rho_{\mathrm{g}}+\rho_{a}} \times \\
& \times F_{0}^{-1 / \lambda_{0}} \int_{h_{2}^{c p}}^{a}\left[D_{a}^{\prime}(a-x)^{\mu_{a}^{\prime}}\right]^{1 / \lambda_{0}} \times \\
& \times \frac{G_{a}^{\prime} A_{c} b_{0}\left(v_{0}-\gamma_{0}\right) x^{v_{0}-\gamma_{0}-1}}{S_{a} k_{0}\left(H_{\max }+R_{\max _{2}}\right)^{v_{0}-\gamma_{0}}} d x=(52) \\
& =\frac{2 \pi \alpha_{a}^{\prime} \rho_{д} \rho_{a} F_{0}^{-1 / \lambda_{0}} G_{a}^{\prime} A_{c} b_{0}}{\left(\rho_{\mathrm{A}}+\rho_{a}\right) S_{a} k_{0}\left(H_{\max }+R_{\max _{2}}\right)^{v_{0}-\gamma_{0}}} \times \\
& \times\left(v_{0}-\gamma_{0}\right)\left(D_{a}^{\prime}\right)^{1 / \lambda} \times{ }_{a} \times \\
& \times\left(a-\frac{h_{2}^{c p}}{2}\right)^{v_{0}-\gamma_{0}-1}\left(h_{2}^{c p}\right)^{\frac{\mu_{a}^{\prime}}{\lambda_{0}}+1} .
\end{aligned}
$$

3 виразів (46) та (47) слідує, що число плям контакту зерен 3 мікронерівностями деталі:

$$
\begin{aligned}
& \mathrm{N}_{\text {уп.пл }}=\frac{\mathrm{G}_{\mathrm{a}}^{\prime} \mathrm{A}_{\mathrm{c}} \mathrm{b}_{0} \mathrm{a}^{v_{0}-\gamma_{0}}}{\mathrm{~S}_{\mathrm{a}} \mathrm{k}_{0}\left(\mathrm{H}_{\max }+\mathrm{R}_{\max _{2}}\right)^{v_{0}-\gamma_{0}}} \times \\
& \times\left[1-\left(1-\frac{\mathrm{h}_{2}^{\mathrm{cp}}}{\mathrm{a}}\right)^{v_{0}-\gamma_{0}}\right] .
\end{aligned}
$$

Наведені формули дозволяють встановити зв'язок між контурним тиском $\mathrm{q}_{\mathrm{c}}=\frac{\mathrm{P}_{\mathrm{cB}}+\mathrm{P}_{\mathrm{a}}^{\prime}+\mathrm{P}_{\mathrm{a}}^{\prime \prime}}{\mathrm{A}_{\mathrm{c}}}$ та наближенням поверхонь, а також зв'язок між відносною площею дотику $t_{p}=\frac{A_{r c B}+A_{a}^{\prime}+A_{a}^{\prime \prime}}{A_{c}}$ і зближенням.

Це стосується безпосередньо характеристики контакту, то треба зауважити, що в даному випадку контурний тиск повинен враховувати динаміку процесу різання і для цього може бути успішно використана наступна залежність:

$$
\begin{aligned}
& \mathrm{q}_{\mathrm{c}}=\frac{\mathrm{FGb}(v-\gamma)}{\mathrm{k}\left(\mathrm{R}_{\text {max }_{1}}+\mathrm{R}_{\text {max }_{2}}\right)^{v-\gamma}\left(1-\mathrm{S}_{\mathrm{a}}\right)} \times \\
& \times \mathrm{B}(\lambda+1, v-\gamma) \times \\
& \times\left(\mathrm{k}_{\mathrm{a}} \mathrm{a}-\mathrm{H}_{\max }+\mathrm{R}_{\text {max }_{1}}\right)^{\lambda+v-\gamma}+ \\
& +\frac{D_{a} G_{a}\left(v_{a}-\gamma_{a}\right) b_{a}}{H_{\max }^{v_{a}-\gamma_{a} k_{a}^{\prime} s_{a}}} \times \\
& \times\left(\mathrm{k}_{\mathrm{a}} \mathrm{a}-\mathrm{R}_{\text {max }_{2}}\right)^{\mu_{\mathrm{a}}+v_{\mathrm{a}}-\gamma_{\mathrm{a}}} \times \\
& \times \mathrm{B}\left(\mu_{\mathrm{a}}+1, v_{\mathrm{a}}-\gamma_{\mathrm{a}}\right)+ \\
& +\frac{D_{a}^{\prime} G_{a}^{\prime} b_{0}\left(v_{0}-\gamma_{0}\right)}{S_{a} k_{0}\left(H_{\text {max }}+R_{\text {max }_{2}}\right)^{v_{0}-\gamma_{0}}\left(\mu_{a}^{\prime}+1\right)} \times \\
& \times\left(k_{a} a-\frac{h_{2}^{c p}}{2}\right)^{v_{0}-\gamma_{0}}-1\left(h_{2}^{c p}\right)^{\mu_{a}^{\prime}+1} \text {, }
\end{aligned}
$$

де $\mathrm{k}_{\mathrm{a}}$ - коефіцієнт, який враховує зміни у зближенні контакт- 
них поверхонь у динаміці. Цей коефіцієнт встановлюється експериментальним шляхом. Відносна опорна довжина профілю $t_{p}$ підраховується таким чином:

$\mathrm{t}_{\mathrm{p}}=\frac{\alpha_{1} \mathrm{~b}\left(\mathrm{k}_{\mathrm{a}} \mathrm{a}-\mathrm{H}_{\text {max }}+\mathrm{R}_{\text {max }_{1}}\right)^{v}}{\left(\mathrm{R}_{\text {max }_{1}}+\mathrm{R}_{\text {max }_{2}}\right)^{v}}+$

$+\frac{\pi \alpha_{a} G_{a}\left(v_{a}-\gamma_{a}\right) \times b_{a}\left(k_{a} a-R_{\max _{2}}\right)^{\mu_{a} / \lambda_{a}+v_{a}-\gamma_{a}}}{H_{\max }^{v_{a}-\gamma_{a} k_{a}^{\prime} S}} \times$

$\times\left(\frac{D_{a}}{F_{a}}\right)^{1 / \lambda_{a}}\left[\begin{array}{l}2 \rho_{a} B\left(\frac{\mu_{a}}{\lambda_{a}}+1, v_{a}-\gamma_{a}\right)- \\ -\left(\frac{D_{a}}{F_{a}}\right)^{1 / \lambda_{a}}\left(k_{a} a-R_{m_{2} x_{2}}\right)^{\mu_{a} / \lambda_{a}} \times \\ \times B\left(\frac{2 \mu_{a}}{\lambda_{a}}+1, v_{a}-\gamma_{a}\right)\end{array}\right]+$

$+\frac{2 \pi \mathrm{a}_{\mathrm{a}} \rho \rho_{\mathrm{a}}}{\rho+\rho_{\mathrm{a}}} \mathrm{F}^{-1 / \lambda_{\mathrm{a}}} \times$

$\times \frac{\mathrm{G}_{\mathrm{a}} \mathrm{b}_{0}\left(\mathrm{v}_{0}-\gamma_{0}\right)}{\mathrm{S}_{\mathrm{a}} \mathrm{k}_{0}\left(\mathrm{H}_{\max }+\mathrm{R}_{\text {max }_{2}}\right)^{v_{0}-\gamma_{0}}} \times$

$\times\left(D_{a}^{\prime}\right)^{1 / \lambda_{0}} \times\left(k_{a} a-\frac{h_{2}^{c p}}{2}\right)^{v_{0}-\gamma_{0}}-1 \times$

$\times\left(h_{2}^{c p}\right)^{\mu_{a}^{\prime} / \lambda_{0}+1}$.

Формула (54) дозволяє встановити зближення а по заданому контурному тиску $\mathrm{q}_{\mathrm{c}}$ (воно $€$ рівнянням відносно а). Оскільки а залежить від коефіцієнту динаміки процесу, то i $t_{p}$ залежить від $\mathrm{k}_{\mathrm{a}}$.

Розрахуємо середню площу плями контакту для контактуючих мікронерівностей деталі та зв'язки інструменту $\Delta \overline{\mathrm{A}}_{\text {ссв, }}$ деталі та абразивних зерен $\Delta \overline{\mathrm{A}}_{\text {ra }}$ і середні сили $\overline{\mathrm{P}_{\text {св }}}$ та $\overline{\mathrm{P}_{\mathrm{a}}}$ для контактучих мікронерівностей системи «деталь-зв'язка інструменту» та «деталь-абразивні зерна»:

$$
\begin{aligned}
& \Delta \bar{A}_{\mathrm{rCB}}=\frac{\overline{A_{\mathrm{rCB}}}}{N_{\mathrm{CB}}}=\frac{\alpha_{1}\left(1-S_{\mathrm{a}}\right) \mathrm{k}}{\mathrm{G}} \times \\
& \times\left(\frac{\mathrm{k}_{\mathrm{a}} \mathrm{a}-\mathrm{H}_{\max }+\mathrm{R}_{\max 1}}{\mathrm{R}_{\text {max }_{1}}+\mathrm{R}_{\text {max }_{2}}}\right)^{v}
\end{aligned}
$$

$\Delta \overline{\mathrm{A}}_{\mathrm{ra}}=\frac{\mathrm{A}_{\mathrm{a}}+\mathrm{A}_{\mathrm{ra}}}{\mathrm{N}_{\text {уп.пл }}+\mathrm{N}_{\text {уп }}}=$

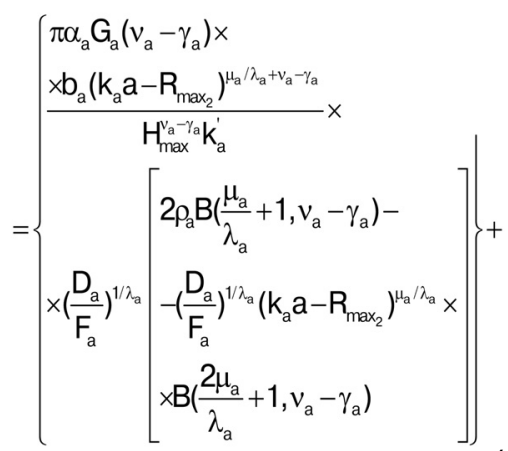

$+\frac{2 \pi \alpha_{a}^{\prime} \rho_{\mathrm{A}} \rho_{\mathrm{a}} \mathrm{F}_{0}^{-1 / \lambda} \mathrm{G}_{\mathrm{a}}^{\prime} \mathrm{b}_{0}\left(v_{0}-\gamma_{0}\right)}{\left(\rho_{\mathrm{g}}+\rho_{\mathrm{a}}\right) \mathrm{S}_{\mathrm{a}} \mathrm{k}_{0}\left(\mathrm{H}_{\max }+\mathrm{R}_{\text {max }_{2}}\right)^{v_{0}-\gamma_{0}}} \times$

$\times\left(D_{a}^{\prime}\right)^{1 / \lambda_{0}} \times\left(k_{a} a-\frac{h_{2}^{c p}}{a}\right)^{v_{0}-\gamma_{0}-1}\left(h_{2}^{c p}\right)^{\mu_{a}^{\prime} / \lambda_{0}+1} \times$

$\times\left\{\begin{array}{l}\frac{G_{a} b_{a}}{k_{a}^{\prime}}\left(\frac{k_{a} a-R_{\max _{2}}}{H_{\text {max }}}\right)^{v_{a}-\gamma_{a}}+\frac{G_{a}^{\prime} b_{0}}{k_{0}} \times \\ \times\left(\frac{k_{a} a}{H_{\max }+R_{\text {max }_{2}}}\right)^{v_{0}-\gamma_{0}} \times\left[1-\left(\left(1-\frac{h_{2}^{c p}}{a}\right)^{v_{0}-\gamma_{0}}\right]\right.\end{array}\right\}^{-1}$.

$\overline{\mathrm{P}_{\mathrm{CB}}}=\frac{\mathrm{P}_{\mathrm{CB}}}{\mathrm{N}_{\mathrm{CB}}}=\mathrm{F}(v-\lambda) \times$

$\times \mathrm{B}(\lambda+1, v-\gamma) \times$

$\times\left(\mathrm{k}_{\mathrm{a}} \mathrm{a}-\mathrm{H}_{\text {max }}+\mathrm{R}_{\text {max }}\right)^{\lambda}$

$\overline{\mathrm{P}_{\mathrm{a}}}=\frac{\mathrm{P}_{\mathrm{a}}^{\prime}+\mathrm{P}_{\mathrm{a}}^{\prime \prime}}{\mathrm{N}_{\text {уп.пл }}+\mathrm{N}_{\text {уп }}}=$

$=\left\{\begin{array}{l}\frac{D_{a} G_{a}\left(v_{a}-\gamma_{a}\right) b_{a}}{H_{m a x}^{v_{a}-\gamma_{a} k_{a}^{\prime} s_{a}} \times} \\ \times\left(k_{a} a-R_{\max 2}\right)^{\mu_{a}+v_{a}-\gamma_{a}} \times \\ \times B\left(\mu_{a}+1, v_{a}-\gamma_{a}\right)+\end{array}\right\} \times$ 


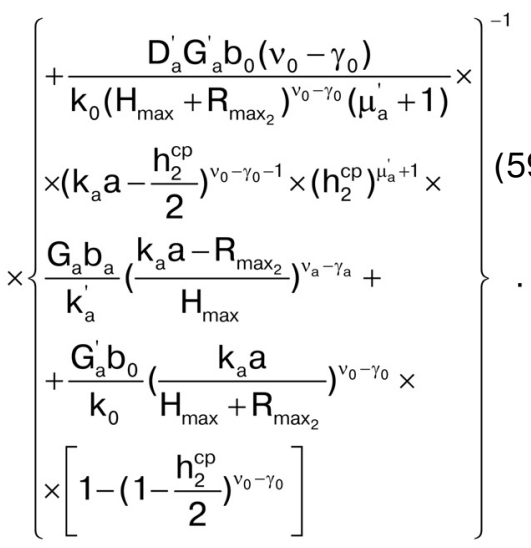

Складнішими $є$ розрахунки питання про об'єм та середню товщину зазору у контакті. Спершу необхідно встановити щільність стику та об'єм зазору між контактуючими поверхнями:

$$
\wedge=\frac{\mathrm{V}_{\mathrm{M}}}{\mathrm{V}_{\mathrm{M}}+\mathrm{V}_{3}},
$$

де $\mathrm{V}_{\mathrm{M}}$ - об'єм матеріалу.

Звідси

$$
\wedge=\frac{\mathrm{V}_{\mathrm{M}_{0}}-\mathrm{V}^{\prime}}{\left(\mathrm{H}_{\max }+\mathrm{R}_{\text {max }_{2}}-\mathrm{k}_{\mathrm{a}} \mathrm{a}\right) \mathrm{A}_{\mathrm{c}}},
$$

де $\mathrm{V}_{\mathrm{M}_{0}}$ - початковий об'єм матеріалу; V' - зменшення об'єму матеріалу.

Не беручи до уваги стискуваність мікровиступів, приймаємо, що V' залежить тільки від переміщення абразивних зерен у зв'язці та втискування їх у деталь:

$$
\mathrm{V}^{\prime}=\Delta \mathrm{V}_{1}+\Delta \mathrm{V}_{2}+\Delta \mathrm{V}_{3}
$$

де $\Delta \mathrm{V}_{1}-$ зміни об'єму зазору за рахунок переміщення пружньопластично контактуючих абразивних зерен; $\Delta \mathrm{V}_{2}-$ зміни об'єму зазору за рахунок переміщення тільки пружньо контактуючих зерен інструменту; $\Delta \mathrm{V}_{3}$ - зміни об'єму зазору за рахунок врізання абразивних зерен у тіло деталі.

\section{Встановимо $\Delta \mathrm{V}_{1}$ :}

$$
\begin{aligned}
& \Delta \mathrm{V}_{1}=\frac{1}{3} \pi \int_{0}^{a_{2}}\left\{\begin{array}{l}
\left(\mathrm{H}_{\max }-\mathrm{x}\right)^{2} \times \\
\times\left(3 \rho_{\mathrm{a}}-\mathrm{H}_{\max }+\mathrm{x}\right)- \\
-\left[\mathrm{H}_{\max }-\mathrm{x}-\mathrm{f}_{2}\left(\mathrm{dP}_{\mathrm{a}}^{\prime}\right)\right]^{2} \times \\
\times\left[3 \rho_{\mathrm{a}}-\mathrm{H}_{\max }+\mathrm{x}+\mathrm{f}_{2}\left(\mathrm{dP}_{\mathrm{a}}^{\prime}\right)\right]
\end{array}\right\} \times \\
& x \mathrm{dN}_{\text {уп.пл }}(\mathrm{x})=\frac{\pi \mathrm{G}_{\mathrm{a}} \mathrm{A}_{\mathrm{c}}\left(\nu_{\mathrm{a}}-\gamma_{\mathrm{a}}\right) \mathrm{b}_{\mathrm{a}}}{3 \mathrm{H}_{\mathrm{max}}^{v_{2}-\gamma_{\mathrm{a}} \mathrm{k}_{\mathrm{a}}^{\prime} \mathrm{S}_{\mathrm{a}}}} \int_{0}^{\mathrm{a}_{2}} \mathrm{x}^{v_{\mathrm{a}}-\gamma_{\mathrm{a}}-1} \mathrm{x} \\
& \times\left\{\begin{array}{l}
\left(H_{\max }-x\right)^{2} \times\left(3 \rho_{a}-H_{\text {max }}+x\right)- \\
-\left[H_{\text {max }}-x_{2}\left(d P_{a}^{\prime}\right)\right]^{2}
\end{array}\right\} x \\
& \times\left[3 \rho_{a}-H_{\max }+x+f_{2}\left(d P_{a}^{\prime}\right)\right] d x \text {, }
\end{aligned}
$$

де

$$
\begin{aligned}
& f_{2}\left(d P_{a}^{\prime}\right)=a_{2}-x- \\
& -\left(\frac{D_{a}}{F_{a}}\right)^{\frac{1}{\lambda_{a}}}\left(a_{2}-x\right)^{\frac{\mu_{a}}{\lambda_{a}}},
\end{aligned}
$$

що слідує з виразів (27-29). Таким чином

$$
\Delta V_{1}=\frac{\pi G_{a} A_{c}\left(v_{a}-\gamma_{a}\right) b_{a}}{3 H_{m a x}^{v_{a}-\gamma_{a k} s_{a}}} \int_{0}^{a_{2}} x^{v_{a}-\gamma_{a}-1}
$$

$\left(H_{\max }-x\right)^{2}\left(3 \rho_{a}-H_{\max }+x\right)-$

$-\left[H_{\max }-a_{2}+\left(\frac{D_{a}}{F_{a}}\right)^{\frac{1}{\lambda_{a}}}\left(a_{2}-x\right)^{\frac{\mu_{a}}{\lambda_{a}}}\right]^{2} \times$

$\times\left[3 \rho_{a}-H_{\max }-a_{2}-\left(\frac{D_{a}}{F_{a}}\right)^{\frac{1}{\lambda_{a}}}\left(a_{2}-x\right)^{\frac{\mu_{a}}{\lambda_{a}}}\right] d x$.

Звідси,

$\frac{\Delta \mathrm{V}_{1}}{\mathrm{~A}_{\mathrm{c}}}=\frac{\pi \mathrm{G}_{\mathrm{a}}\left(v_{\mathrm{a}}-\gamma_{\mathrm{a}}\right) \mathrm{b}_{\mathrm{a}}}{3 \mathrm{H}_{\max }^{v_{\mathrm{a}}-\gamma_{\mathrm{a}} \mathrm{s}_{\mathrm{a}}}} \times$

$\times\left\{a_{2}^{v_{a}-\gamma_{a}}\left[\frac{H_{\text {max }}^{2}\left(3 \rho_{a}-H_{\max }\right)}{v_{a}-\gamma_{a}}-\right.\right.$

$-\frac{3 a_{2} H_{\max }\left(2 \rho_{a}-H_{\max }\right)}{v_{a}-\gamma_{a}+1}+$

$\left.+\frac{3 a_{a}^{2}\left(\rho_{a}-H_{\max }\right)}{v_{a}-\gamma_{a}+2}+\frac{a_{a}^{2}}{v_{a}-\gamma_{a}+3}\right]+$ 


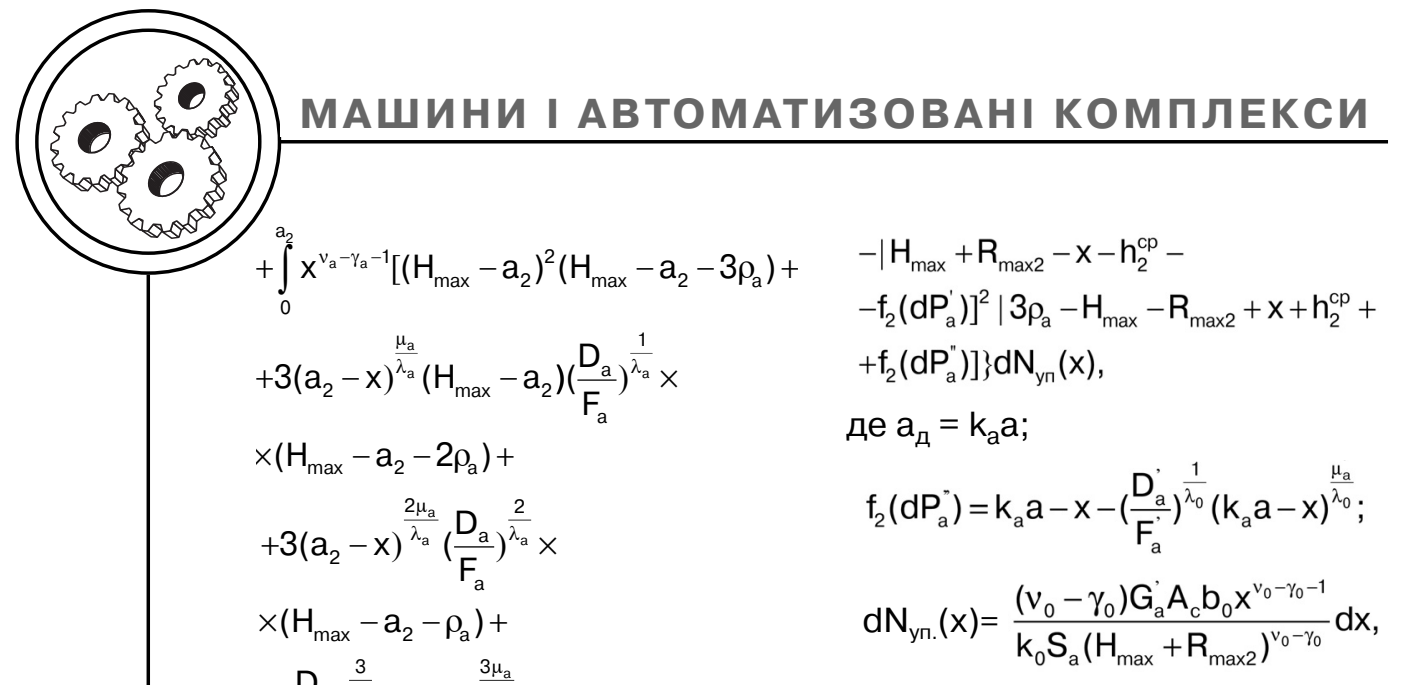

$\left.\left.+\left(\frac{\mathrm{D}_{\mathrm{a}}}{\mathrm{F}_{\mathrm{a}}}\right)^{\frac{3}{\lambda_{\mathrm{a}}}}\left(\mathrm{a}_{2}-\mathrm{x}\right)^{\frac{3 \mu_{\mathrm{a}}}{\lambda_{\mathrm{a}}}}\right] \mathrm{dx}\right\}=$

$=\frac{\pi \mathrm{G}_{\mathrm{a}}\left(v_{\mathrm{a}}-\gamma_{\mathrm{a}}\right) \mathrm{b}_{\mathrm{a}}}{3 \mathrm{H}_{\max }^{v_{\mathrm{a}}-\gamma_{\mathrm{a}} \mathrm{k}_{\mathrm{a}} \mathrm{s}_{\mathrm{a}}}} \mathrm{a}^{v_{\mathrm{a}}-\gamma_{\mathrm{a}}} \times$

що витікає з формул (39-41) і

(46).

Звідси

$\times\left\{\left[\frac{\mathrm{H}_{\max }^{2}\left(3 \rho_{\mathrm{a}}-\mathrm{H}_{\max }\right)}{v_{\mathrm{a}}-\gamma_{\mathrm{a}}}-\right.\right.$

$\frac{\Delta \mathrm{V}_{2}}{\mathrm{~A}_{\mathrm{c}}} \approx \frac{1}{3} \pi \int_{\mathrm{a}_{\mathrm{A}}-\mathrm{h}_{2}^{\mathrm{cp}}}^{\mathrm{a}_{\mathrm{p}}}\left\{\left(\mathrm{H}_{\max }+\mathrm{R}_{\max }-\mathrm{x}-\mathrm{h}_{2}^{\mathrm{cp}}\right)^{2} \times\right.$

$-\frac{3 \mathrm{a}_{2} \mathrm{H}_{\max }\left(2 \rho_{\mathrm{a}}-\mathrm{H}_{\max }\right)}{v_{\mathrm{a}}-\gamma_{\mathrm{a}}+1}+$

$\times\left(3 \rho_{\mathrm{a}}-\mathrm{H}_{\max }-\mathrm{R}_{\max }+\mathrm{x}+\mathrm{h}_{2}^{\mathrm{cp}}\right)-$

$-\left[\mathrm{H}_{\max }+\mathrm{R}_{\max }-\mathrm{h}_{2}^{\mathrm{cp}}-\mathrm{k}_{\mathrm{a}} \mathrm{a}+\right.$

$\left.+\frac{3 a_{2}^{2}\left(\rho_{a}-H_{\max }\right)}{v_{a}-\gamma_{a}+2}+\frac{a_{2}^{3}}{v_{a}-\gamma_{a}+3}\right]-$

$\left.+\left(\frac{D_{a}^{\prime}}{F_{0}}\right)^{\frac{1}{\lambda_{0}}}\left(k_{a} a-x\right)^{\frac{\mu_{a}^{\prime}}{\lambda_{0}}}\right]^{2}\left[3 \rho_{a}-H_{\max }-R_{\max 2}+\right.$

$-\left[\frac{\left(\mathrm{H}_{\max }-\mathrm{a}_{2}\right)^{2}\left(3 \rho_{\mathrm{a}}+\mathrm{a}_{2}-\mathrm{H}_{\max }\right)}{v_{\mathrm{a}}-\gamma_{\mathrm{a}}}+\right.$

$\left.\left.+\mathrm{h}_{2}^{\mathrm{cp}}+\mathrm{k}_{\mathrm{a}} \mathrm{a}-\left(\frac{\mathrm{D}_{\mathrm{a}}^{\prime}}{\mathrm{F}_{0}}\right)^{\frac{1}{\lambda_{0}}}\left(\mathrm{k}_{\mathrm{a}} \mathrm{a}-\mathrm{x}\right)^{\frac{\mu_{\mathrm{a}}^{\prime}}{\lambda_{0}}}\right]\right\} \times$

$+3 a_{2}^{\frac{\mu_{a}}{\lambda_{a}}}\left(H_{\max }-a_{2}\right) \times$

$\times\left(\frac{D_{a}}{F_{a}}\right)^{\frac{1}{\lambda_{a}}}\left(2 \rho_{a}+a_{2}-H_{\max }\right) \times$

$\times \frac{\left(v_{0}-\gamma_{0}\right) G_{a}^{\prime} b_{0} x^{v_{0}-\gamma_{0}-1}}{k_{0} S_{a}\left(H_{\max }+R_{\max 2}\right)^{v_{0}-\gamma_{0}}} d x \approx$

$\approx \frac{1}{3} \pi \frac{\left(v_{0}-\gamma_{0}\right) G_{a}^{\prime} b_{0}\left(k_{a} a-\frac{h_{2}^{c p}}{2}\right)^{v_{0}-\gamma_{0}-1}}{k_{0} S_{a}\left(H_{\max }+R_{\max 2}\right)^{v_{0}-\gamma_{0}}} \times$

$\times \mathrm{B}\left(v_{\mathrm{a}}-\gamma_{\mathrm{a}}, \frac{\mu_{\mathrm{a}}}{\lambda_{\mathrm{a}}}+1\right)+$

$\times \int_{0}^{\mathrm{h}_{2}^{\mathrm{cp}}}\left\{\left(\mathrm{H}_{\max }+\mathrm{R}_{\max 2}-\mathrm{h}_{2}^{\mathrm{cp}}-\mathrm{k}_{\mathrm{a}} \mathrm{a}+\mathrm{t}\right)^{2} \times\right.$

$+3 a_{2}^{\frac{2 \mu_{a}}{\lambda_{a}}}\left(\frac{D_{a}}{F_{a}}\right)^{\frac{2}{\lambda_{a}}}\left(\rho_{a}+a_{2}-H_{\max }\right) \times$

$\times \mathrm{B}\left(v_{\mathrm{a}}-\gamma_{\mathrm{a}}, \frac{2 \mu_{\mathrm{a}}}{\lambda_{\mathrm{a}}}+1\right)-$

$\times\left(3 p_{\mathrm{h}}-\mathrm{H}_{\max }-\mathrm{R}_{\max 2}+\mathrm{h}_{2}^{\mathrm{cp}}+\mathrm{k}_{\mathrm{a}} \mathrm{a}-\mathrm{t}\right)-$

$-\left[\mathrm{h}_{\max }+\mathrm{R}_{\max 2}-\mathrm{h}_{2}^{\mathrm{cp}}-\mathrm{k}_{\mathrm{a}} \mathrm{a}+\right.$

$\left.\left.-3 \mathrm{a}_{2}^{\frac{3 \mu_{\mathrm{a}}}{\lambda_{\mathrm{a}}}}\left(\frac{\mathrm{D}_{\mathrm{a}}}{\mathrm{F}_{\mathrm{a}}}\right)^{\frac{3}{\lambda_{\mathrm{a}}}} \mathrm{B}\left(v_{\mathrm{a}}-\gamma_{\mathrm{a}}, \frac{3 \mu_{\mathrm{a}}}{\lambda_{\mathrm{a}}}+1\right)\right]\right\}$,

$\left.+\left(\frac{D_{a}^{\prime}}{F_{0}}\right)^{1 / \lambda_{0}} t^{\mu_{a}^{\prime} / \lambda_{0}}\right]^{2} \times$

де $\mathrm{a}_{2}=\mathrm{k}_{\mathrm{a}} \mathrm{a}-\mathrm{R}_{\max 2}$.

Розрахуємо $\Delta \mathrm{V}_{2}$ :

$\times\left[3 \rho_{\mathrm{a}}-\mathrm{H}_{\max }-\mathrm{R}_{\max 2}+\mathrm{h}_{2}^{\mathrm{cp}}+\right.$

$\left.\left.+\mathrm{k}_{\mathrm{a}} \mathrm{a}-\left(\frac{\mathrm{D}_{\mathrm{a}}^{\prime}}{\mathrm{F}_{0}}\right)^{1 / \lambda_{0}} \mathrm{t}^{\mu_{\mathrm{a}}^{\prime} / \lambda_{0}}\right]\right\} \mathrm{dt}=$

$\Delta \mathrm{V}_{2} \approx \frac{1}{3} \pi \int_{\mathrm{a}_{\mathrm{B}}-\mathrm{h}_{2}^{\mathrm{p}}}^{\mathrm{a}_{\mathrm{p}}}\left\{\left(\mathrm{H}_{\max }+\mathrm{R}_{\max 2}-\mathrm{x}-\mathrm{h}_{2}^{\mathrm{cp}}\right)^{2} \times-\right.$

$=\frac{1}{3} \pi \frac{\left(v_{0}-\gamma_{0}\right) G_{a}^{\prime} b_{0}\left(k_{a} a-\frac{h_{2}^{c p}}{2}\right)^{v_{0}-\gamma_{0}-1}}{k_{0} S_{a}\left(H_{\max }+R_{\max 2}\right)^{v_{0}-\gamma_{0}}} \times$ 
$\times\left[\frac{3}{2}\left(h_{2}^{c p}\right)^{2} H_{0}\left(2 \rho_{a}-H_{0}\right)+\left(h_{2}^{c p}\right)^{3}\left(\rho_{a}-H_{0}\right)-\right.$

$-\frac{1}{4}\left(h_{2}^{c p}\right)^{4}-3 H_{0}\left(\frac{D_{a}^{\prime}}{F_{0}}\right)^{1 / \lambda_{0}}\left(2 \rho_{a}-H_{0}\right) \times$

$\times \frac{\left(h_{2}^{c p}\right)^{1+\mu_{a}^{\prime} / \lambda_{0}}}{1+\frac{\mu_{a}^{\prime}}{\lambda_{0}}}-3\left(\frac{D_{a}^{\prime}}{F_{0}}\right)^{2 / \lambda_{0}} \times$

$\times \frac{\left(\rho_{\mathrm{a}}-\mathrm{H}_{0}\right)\left(\mathrm{h}_{2}^{\mathrm{cp}}\right)^{1+2 \mu_{\mathrm{a}}^{\prime} / \lambda_{0}}}{1+\frac{2 \mu_{\mathrm{a}}^{\prime}}{\lambda_{0}}}+$

$\left.+\left(\frac{D_{a}^{\prime}}{F_{0}}\right)^{3 / \lambda_{0}} \frac{\left(h_{2}^{c p}\right)^{1+3 \mu_{a}^{\prime} / \lambda_{0}}}{1+\frac{3 \mu_{a}^{\prime}}{\lambda_{0}}}\right]$

$$
\mathrm{H}_{0}=\mathrm{H}_{\max }+\mathrm{R}_{\max 2}-
$$$$
-\mathrm{h}_{2}^{\mathrm{cp}}-\mathrm{k}_{\mathrm{a}} \mathrm{a} \text {. }
$$

Розрахуємо $\Delta \mathrm{V}_{3}$ :

$$
\Delta \mathrm{V}_{3}=\frac{1}{3} \pi \int_{0}^{\mathrm{a}_{2}}\left[\mathrm{f}_{1}\left(\mathrm{dP}_{\mathrm{a}}^{\prime}\right)\right]^{2}\left[3 \mathrm{f}_{1}\left(\mathrm{dP}_{\mathrm{a}}^{\prime}\right)\right] \mathrm{x}^{\mathrm{v}_{\mathrm{a}}-\gamma_{\mathrm{a}} 1} \mathrm{dx},
$$

де $f_{1}\left(d P_{a}^{\prime}\right)=F_{a}^{-1 / \lambda_{a}}\left(d P_{a}^{\prime}\right)^{1 / \lambda_{a}}=$

$$
=\left(\frac{D_{a}}{F_{a}}\right)^{1 / \lambda_{a}}\left(a_{2}-x\right)^{\mu_{a} / \lambda_{a}} .
$$

Таким чином,

$$
\begin{aligned}
& \frac{\Delta V_{3}}{A_{c}}=\frac{1}{3} \pi \frac{G_{a}\left(v_{a}-\gamma_{a}\right) b_{a}}{H_{\max }^{v_{a}-\gamma_{a} k_{a}^{\prime} s_{a}}}\left(\frac{D_{a}}{F_{a}}\right)^{2 / \lambda_{a}} \times \\
& \times\left(k_{a} a-R_{\max 2}\right)^{v_{a}-\gamma_{a}+2 \mu_{a} / \lambda_{a}} \times \\
& \times \int_{0}^{1} t^{v_{a}-\gamma_{a}-1}(1-t)^{2 \mu_{a} / \lambda_{a}} \times \\
& \times\left[3 \rho_{a}-\left(\frac{D_{a}}{F_{a}}\right)^{\frac{1}{\lambda_{a}}}\left(k_{a} a-R_{\max 2}\right)^{\mu_{a} / \lambda_{a}} \times\right. \\
& \left.\times(1-t)^{\mu_{a} / \lambda_{a}}\right] d t= \\
& \left.=\frac{1}{3} \pi \frac{G a}{H_{a}\left(v_{a}-\gamma_{a}\right) b_{a}}\left(\frac{D_{a}}{F_{a}-\gamma_{a x} k_{a}^{\prime} s_{a}}\right)^{\frac{2}{\lambda_{a}}}\right) \times \\
& \quad \times\left(k_{a} a-R_{\max 2}\right)^{v_{a}-\gamma_{a}+2 \mu_{a} / \lambda_{a}} \times \\
& \times\left[3 \rho_{a} B\left(v_{a}-\gamma_{a}, 1+2 \mu_{a} / \lambda_{a}\right)-\right. \\
& \quad-\left(\frac{D_{a}}{F_{a}}\right)^{1 / \lambda_{a}}\left(k_{a} a-R_{\max 2}\right)^{\mu_{a} / \lambda_{a}} \times \\
& \times \\
& \left.\times B\left(v_{a}-\gamma_{a}, 1+3 \mu_{a} / \lambda_{a}\right)\right] .
\end{aligned}
$$

Позначимо $\mathrm{x}=\frac{\mathrm{V}^{\prime}}{\mathrm{A}_{\mathrm{c}}}, \mathrm{x}$ знахоходиться за формулами (62), (66), (68), (70). Далі розраховуємо V. Скористуємось тим, що коефіцієнт заповнення профіля при умові, що основи нерівностей покривають усю контурну площу, складає:

$$
\mathrm{k}_{3} \approx 1-(2 \mathrm{~b})^{-\frac{1}{v}}
$$

Тоді

$$
\begin{aligned}
& \frac{\mathrm{V}_{\mathrm{M} 0}}{\mathrm{~A}_{\mathrm{c}}}=\left[1-\left(2 \mathrm{~b}_{2}\right)^{-1 / \mathrm{v}_{2}}\right] \mathrm{R}_{\max }+ \\
& +\left[1-\left(\frac{\mathrm{S}_{\mathrm{a}}}{2 \mathrm{~b}_{\mathrm{a}}}\right)^{1 / \mathrm{v}_{\mathrm{a}}}\right] \mathrm{H}_{\max _{\mathrm{a}}}+ \\
& +\left[1-\left(\frac{1-\mathrm{S}_{\mathrm{a}}}{2 \mathrm{~b}_{1}}\right)^{1 / \mathrm{v}_{1}}\right] \mathrm{R}_{\max \left(1-\mathrm{S}_{\mathrm{a}}\right)}
\end{aligned}
$$

Остаточно отримуємо:

$$
\begin{aligned}
& \Lambda=\frac{1}{\mathrm{H}_{\max }+\mathrm{R}_{\max }-\mathrm{k}_{\mathrm{a}} \mathrm{a}} \times \\
& \times\left\{\left[1-\left(2 b_{2}\right)^{-1 / v_{2}}\right] R_{\max 2}+\right. \\
& +\left[1-\left(\frac{\mathrm{S}_{\mathrm{a}}}{2 \mathrm{~b}_{2}}\right)^{1 / \mathrm{v}_{\mathrm{a}}}\right] \mathrm{H}_{\max } \mathrm{S}_{\mathrm{a}}+ \\
& +\left[1-\left(\frac{1-S_{a}}{2 b_{1}}\right)^{1 / v_{1}}\right] \times \\
& \left.\times \mathrm{R}_{\max 1}\left(1-\mathrm{S}_{\mathrm{a}}\right)-x\right\} \text {; } \\
& \mathrm{V}_{\mathrm{M}}=\Lambda\left(\mathrm{H}_{\max }+\mathrm{R}_{\max 2}-\mathrm{k}_{\mathrm{a}} \mathrm{a}\right) \cdot \mathrm{A}_{\mathrm{C}} \text {; } \\
& \mathrm{V}_{3}=(1-\Lambda) \times \\
& \times\left(\mathrm{H}_{\max }+\mathrm{R}_{\max 2}-\mathrm{k}_{\mathrm{a}} \mathrm{a}\right) \mathrm{A}_{\mathrm{c}} \text {. }
\end{aligned}
$$


реміщення абразивних зерен у зв'язці інструменту і сприймати абразивний інструмент тільки як однорідне шорстке тверде тіло. При цьому профілограма поверхні вважається єдиною без поділення на зв'язку і абразивні зерна. Таке припущення (у першому наближенні) можливе лише при умові застосування найміцніших зв'язок інструменту (наприклад, металевих підвищеної міцності). У випадку застосування менш міцних зв'язок (керамічної, еластичної гліфталевої) треба усвідомлюювати, що точність розрахунків (ще до початку їх виконання) може знизити очікуванні кінцеві результати щонайменше на 7-10 \%.

Для оціночних інженерних розрахунків можливо скористатися підходами, наведеними у роботах $[1,17,27-29]$ з урахуванням особливостей надтонкої висікально-оздоблювальної абразивної обробки. 3 урахуванням цього, зазначимо, що фактична площа контакту при пружній деформації мікровиступів визначається згідно формулі:

$$
\begin{aligned}
& A_{r}=\left[2,35\left(\frac{A_{c} b}{2}\right)^{1 / 2 v} \times\right. \\
& \left.\times \frac{\mid \rho^{1 / 2} P_{y}}{k_{3} R_{\max }^{1 / 2}}\right]^{\frac{2 v}{2 v+1}},
\end{aligned}
$$

де $\mathrm{k}_{\mathrm{r}}$ - коефіцієнт динаміки зміни фактичної зміни контакту. I - пружна постійна контакту, $\rho-$ приведений радіус, контактуючих тіл, $\mathrm{P}_{\mathrm{y}}$ - радіальна складова сили різання;

$$
\begin{gathered}
v=v_{n}+v_{d} ; \\
b=\frac{k_{2} b_{n} b_{\partial} R_{\max }^{v}}{R_{\operatorname{maxn}}^{v_{n}} R_{\max }^{v_{\partial}}} ;
\end{gathered}
$$

$$
\begin{gathered}
\mathrm{R}_{\max }=\mathrm{R}_{\operatorname{maxu}}+\mathrm{R}_{\max \partial} ; \\
\mathrm{I}=\frac{1-\mu_{n}^{2}}{\mathrm{E}_{n}}+\frac{1-\mu_{\partial}^{2}}{\mathrm{E}_{\partial}} ; \\
\rho=\frac{\rho_{n} \rho_{\partial}}{\rho_{n}+\rho_{\partial}} ;
\end{gathered}
$$

де $v_{n}$ i $b_{n}$; $v_{д}$ i $b_{д}-$ параметри опорних кривих поверхонь інструменту і деталі; $\mathrm{R}_{\max }$ i $\mathrm{R}_{\max \partial}$ - максимальна висота мікронерівностей поверхонь відповідно інструменту та деталі; $E_{n}, \mu_{n}, \rho_{n}, E_{д}, \mu_{д}$ і $\rho_{д}-$ модулі пружності, коефіцієнти Пуасона та радіуси сфер інструменту і деталі; $\mathrm{k}_{2}$ i k римані в результаті чисельного рішення початкових інтегральних рівнянь, що встановлюють в залежності від $v$ за даними роботи [1].

Радіальну складову сили різання $\mathrm{P}_{\mathrm{r}}$ і коефіцієнт динаміки $\mathrm{K}_{r}$, який враховує зміни величин площ контакту при переході від покою до ковзання, встановлюють експериментально чи шляхом розрахунків.

У зв'язку з тим, що при абразивній обробці у зоні різання утворюються значні температури [24, 26-29], для розрахунків контакту фізико-механічні характеристики тіл взаємодії визначаються їх показниками при температурах поверхневих шарів, у зоні яких відбувається деформація.

При пластичному контакті фактична площа контакту розраховується за формулою:

$$
\mathrm{A}_{\mathrm{r}}=\mathrm{k}_{\mathrm{r}} \frac{\mathrm{P}_{\mathrm{y}}}{\mathrm{C} \sigma_{\mathrm{T}}}=\mathrm{k}_{\mathrm{r}} \frac{\mathrm{P}_{\mathrm{y}}}{\mathrm{HB}} .
$$

Проте найбільш типовим $є$ пружньо-пластична взаємодія 
абразивного інструменту з деталлю. При цьому абразивні зерна, втискуючись у оброблюваний метал, деформують його пружньо-еластично, а зв'язка інструменту контактує з поверхнею деталі, що оброблюється, лише пружньо.

Одночасно відбувається пружнє занурення абразивів у зв'язці інструменту. У випадку пластичної деформації зв'язки відбувається катастрофічний знос абразивного інструменту та його руйнація.

При пружнопластичному контакті, фактична площа контакту

$$
\begin{aligned}
& A_{r}=k_{r}\left[\frac{P_{y}}{c \sigma_{T}}+\right. \\
& \left.+\frac{\left(b A_{c}\right)^{1 / v} v_{k}\left(\frac{P_{y}}{c \sigma_{T}}\right)}{2 R_{\max }}\right],
\end{aligned}
$$

де $\mathrm{a}_{\mathrm{k}}$ - критичне абсолютне зближення, яке засвідчує перехід контакту з пружного стану у пластичний.

Розрахунки за формулою (83) доцільні лише у випадку, якщо $a_{k}$ приблизно співпадає зі зближенням а від пружньої та пластичної складових процесу. В іншому випадку розрахунок виконується за формулами для умов пластичного контакту.

Зазначемо, що під дією радіальної складової сили різання відбувається зближення поверхонь абразивного інструменту та деталі. При пружньому контакті числові значення абсолютного зближення у даних умовах знаходять за формулою:

$$
a=k_{a}\left(\frac{4,7 \mid \rho^{1 / 2} P_{y} R_{\max }^{v}}{k_{3} A_{c} b}\right)^{\frac{2}{2 v+1}},
$$

а при пластичному контакті:

$$
a=k_{a} R_{\max }\left(\frac{P_{y}}{A_{c} c \sigma_{T} b}\right)^{1 / v},
$$

де $\mathrm{k}_{\mathrm{a}}$ - коефіцієнт динаміки для зближення поверхонь.

При пружно-пластичному контакті загальне зближення поверхонь контакту складається з пружної та пластичної складових цього зближення. Це зближення не у повній мірі відповідає глибині занурення абразивних зерен інструменту з поверхнею оброблення металу, тобто глибині різання, тому що при контактній взаємодії абразивні зерна дещо зсуваються у тілі зв'язки інструменту, а величина та характер цього переміщення змінюються у широкому діапазоні в залежності від фізико-механічних властивостей зв'язки та оброблюваного матеріалу.

Зближення ж хвилеподібних поверхонь на початку циклу оброблення деталі являє собою суму зближень від деформації мікровиступів та хвиль. Стик двох шорстких поверхонь характеризується контактною жорсткістю, яка встановлюється збільшенням питомого тиску до відповідного зростання взаємного переміщення спряжених поверхонь у тому ж напрямку. Взаємодія абразивного інструменту з деталлю передбачає занурення абразивних зерен в оброблюваний матеріал. Тому для стику пари «абразивний інструмент-деталь» підраховують зворотню величину - контактну піддатливість.

В загальному випадку контактна податливість розраховується за формулою: 


$$
\omega=\frac{\mathrm{da}}{\mathrm{dq}_{\mathrm{c}}},
$$

д $\mathrm{e}$

da - приріст абсолютного зближення; $\mathrm{dq}_{\mathrm{c}}-$ приріст контурного тиску.

При пружному контакті середня контактна податливість розраховується за формулою:

$$
\begin{aligned}
& \omega_{c p}=k_{a}\left(\frac{P_{y}}{A_{c}}\right)^{\frac{1-2 v}{1+2 v}} \times \\
& \times\left(\frac{4,7 \mid \rho^{1 / 2} R_{\max }^{v}}{k_{3} b}\right)^{\frac{2}{1+2 v}},
\end{aligned}
$$

а при пластичному контакті:

$$
\omega_{c p}=k_{a} R_{\max }\left[\frac{1}{c \sigma_{\mathrm{T}} \mathrm{b}}\left(\frac{\mathrm{A}_{\mathrm{c}}}{\mathrm{P}_{\mathrm{y}}}\right)^{\mathrm{v}-1}\right]^{1 / \mathrm{v}} .
$$

Номінальне $q_{a}$, контурне $q_{c} i$ фактичне $\mathrm{q}_{\mathrm{r}}$ значення тиску в контакті визначають за формулами:

$$
q_{a}=\frac{P_{y}}{A_{a}} ; q_{c}=\frac{P_{y}}{A_{c}} ; q_{r}=\frac{P_{y}}{A_{r}} .
$$

При абразивній обробці безпосередньо на процес різання значно впливає об'єкт (товщина) зазору у контакті інструменту з деталлю, тобто простір між рельєфами інструменту та деталі після зближення їх під дією прикладеного навантаження радіальної складової сили різання (сили тиску).

Вибір оптимального об'єму зазору для збереження розміщення та виходу із зони різання стружки (при умові заданої продуктивності оброблення) $є$ визначальною умовою нормального перебігу процесу різання. Недостатній об'єм для розміщення стружки веде до засалювання абразивного інструменту і суттєвому зменшенню його експлуатаційних показників.
Об'єкт зазору при пружному контакті знаходять з умов:

$$
\begin{aligned}
& \mathrm{V}_{3}=\left[\left(\frac{1}{2 b}\right)^{1 / v}-\right. \\
& \left.-\mathrm{k}_{\mathrm{a}}\left(\frac{4,7 \mid \rho^{1 / 2} \mathrm{P}_{\mathrm{y}}}{\mathrm{k}_{3} \mathrm{R}_{\max }^{1 / 2} \mathrm{bA}}\right)^{\frac{2}{2 v+1}}\right] R_{\max } A_{c},
\end{aligned}
$$

а при пластичному контакті:

$$
\begin{aligned}
& V_{3}=\left[\left(\frac{1}{2 b}\right)^{1 / v}-\right. \\
& \left.-k_{a}\left(\frac{P_{y}}{A_{c} c \sigma_{T} b}\right)^{\frac{1}{v}}\right] R_{\text {max }} A_{c} .
\end{aligned}
$$

Середня товщина зазору $\overline{\mathrm{h}_{3}}$ у контакті визначається як контурна площа, що поділена на об'єм зазору. Важливими параметрами контакту абразивного інструменту з деталлю $є$ розмір та кількість плям контакту.

Форма одиничних мікровиступів може бути виписана фунцією:

$$
\psi(\varepsilon)=\frac{\overline{\Delta \mathrm{A}_{\mathrm{r}}}}{\overline{\Delta \mathrm{A}_{\mathrm{c}}}}=\mathrm{k} \varepsilon^{\gamma},
$$

де $\overline{\Delta \mathrm{A}_{\mathrm{r}}}$ - середня величина фактичної площі контакту одиничного мікровиступу при даному зближенні; $\overline{\Delta \mathrm{A}_{\mathrm{c}}}-$ середня площа основи мікровиступу.

Для прийнятої сферичної моделі $\gamma=1 \mathrm{i} k=\frac{1}{v}$.

Тоді

$$
\frac{\overline{\Delta \mathrm{A}_{\mathrm{r}}}}{\overline{\Delta \mathrm{A}_{\mathrm{c}}}}=\frac{1}{\mathrm{v}} \varepsilon,
$$

чи

$$
\overline{\Delta \mathrm{A}_{\mathrm{r}}}=\frac{\overline{\Delta \mathrm{A}_{\mathrm{c}}}}{\mathrm{v}} \varepsilon .
$$

У той же час відомо, що

$$
t_{p}=\frac{A_{r}}{A_{c}}=b \varepsilon^{v}
$$




$$
\varepsilon=\left(\frac{A_{r}}{A_{c} b}\right)^{1 / v} .
$$

Тоді середня площа контакту одиничного виступу при умові статичного навантаження визначається виразом:

$$
\overline{\Delta A_{r}}=\frac{\overline{\Delta A_{c}}}{v}\left(\frac{A_{r}}{A_{c} b}\right)^{1 / v} .
$$

3 урахуванням динаміки процесу різання при абразивній обробці

$$
\overline{\Delta \mathrm{A}_{\mathrm{rd}}}=\frac{\overline{\Delta \mathrm{A}_{\mathrm{c}}}}{\mathrm{v}}\left(\frac{\mathrm{k}_{\mathrm{r}} \mathrm{A}_{\mathrm{r}}}{\mathrm{A}_{\mathrm{c}} \mathrm{b}}\right)^{1 / \mathrm{v}} .
$$

Для умов контактування двох шорстких поверхонь

$$
\overline{\Delta \mathrm{A}_{\mathrm{c}}}=\frac{\overline{2 \Delta \mathrm{A}_{\mathrm{c} 1} \Delta \mathrm{A}_{\mathrm{c} 2}}}{\overline{\Delta \mathrm{A}_{\mathrm{c} 1}}+\overline{\Delta \mathrm{A}_{\mathrm{c} 2}}},
$$

де $\overline{\Delta \mathrm{A}_{\mathrm{c}}} \mathrm{i} \overline{\Delta \mathrm{A}_{\mathrm{c} 2}}$ - середні площі основ мікровиступів контактуючих поверхонь.

Для сферичної моделі мікровиступів

$$
\overline{\Delta \mathrm{A}_{\mathrm{c}}}=\frac{\pi \mathrm{S}_{\mathrm{m}}^{2}}{4},
$$

де $S_{m}-$ крок мікронерівностей.

Таким чином,

$$
\overline{\Delta A_{c}}=\frac{2 \pi S_{m 1}^{2} S_{m 2}^{2}}{S_{m 1}^{2}+S_{m 2}^{2}},
$$

де $S_{m 1}$ i $S_{m 2}$ - кроки мікронерівностей контактуючих поверхонь.

Кількість плям контакту при статичному навантаженні:

$$
\begin{aligned}
& \mathrm{n}_{\mathrm{r}}=\frac{\mathrm{A}_{\mathrm{r}}}{\Delta \mathrm{A}_{\mathrm{r}}}=\frac{\mathrm{v}}{\overline{\Delta \mathrm{A}_{\mathrm{c}}}} \times \\
& \times\left(\mathrm{A}_{\mathrm{c}} \mathrm{b}\right)^{1 / \mathrm{v}} \mathrm{A}_{\mathrm{r}}^{\frac{\mathrm{v}-1}{\mathrm{v}}},
\end{aligned}
$$

а при динамічному навантаженні:

$$
n_{r 4}=\frac{v}{\overline{\Delta A_{c}}}\left(A_{c} b\right)^{1 / v} \times\left(k_{r} A_{r}\right)^{\frac{v-1}{v}},(103)
$$

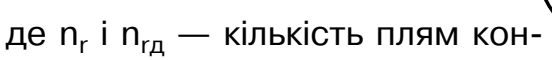
такту при статичному i динамічному навантаженні.

Формули (98) і (103) можуть бути записані таким чином:

$$
\begin{gathered}
\overline{\Delta \mathrm{A}_{\mathrm{rg}}}=\mathrm{k}_{\mathrm{r}}^{1 / \mathrm{v}} \Delta \mathrm{A}_{\mathrm{r}}, \\
\mathrm{n}_{\mathrm{rg}}=\mathrm{k}_{\mathrm{r}}^{\frac{\mathrm{v}-1}{\mathrm{v}}} \mathrm{n}_{\mathrm{r}} .
\end{gathered}
$$

Так як $v=v_{u}+v_{д}>2$, із аналізу формул (104) і (105) видно, що фактична площа контакту в динаміці зростає здебільше зі збільшенням кількості плям контакту i, у значно меншому ступені, внаслідок зростання площ одиничних плям контакту.

Збільшення фактичної площі контакту внаслідок зростання площі одиничних контактів визначається наступною формулою:

$$
\Delta A_{r 1}=\left(k_{r}^{1 / v}-1\right) \overline{\Delta A_{r}} n_{r},
$$

а за рахунок збільшення плям контакту:

$$
\Delta \mathrm{A}_{\mathrm{r}_{2}}=\left(\mathrm{k}_{\mathrm{r}}^{\mathrm{v}}-\mathrm{k}_{\mathrm{r}}^{1 / \mathrm{v}}\right) \overline{\Delta \mathrm{A}_{\mathrm{r}}} \mathrm{n}_{\mathrm{r}} .
$$

Як приклад наведемо результати розрахунків параметрів 100-го такту при хонінгуванні отворів нових підшипників ковзання для швидкісних офсетних поліграфічних машин, які виготовлені з високолегованого та зносостійкого матеріалу 86Х6НФТ з 5 \% вмістом твердого мастила $\mathrm{C}_{2} \mathrm{~F}_{2}$, синтезованого 3 відходів інструментальної сталі. Для розрахунків враховані такі дані: хонінгують підшипник ковзання з внутрішнім діаметром 50 мм, довжиною 85 мм 3 композиту 86Х6НФТ + $5 \%$ С (HВ = 780-800 МПа) абразивни- 
Розрахунки параметрів контакту пари «композитний підшипник-хонінгувальний брусок»

\begin{tabular}{|c|c|c|}
\hline $\begin{array}{c}\text { Характеристика } \\
\text { абразиву }\end{array}$ & 63сМ28СМ2Гл & 63С5СМ2Гл \\
\hline$v_{a}$ & 1,21 & 2,39 \\
\hline$v_{\mathrm{u}}$ & 0,68 & 1,65 \\
\hline$v$ & 2,15 & 3,21 \\
\hline$b_{A}$ & 1,10 & 2,01 \\
\hline$b_{u}$ & 1,05 & 1,76 \\
\hline$b$ & 72 & 56 \\
\hline $\mathrm{R}_{\max }, \mathrm{MKM}$ & 5,3 & 7,8 \\
\hline $\mathrm{R}_{\max }, \mathrm{MKM}$ & 55,1 & 69,7 \\
\hline a, MKM & 2,17 & 3,51 \\
\hline $\mathrm{V}_{3}, \mathrm{MM}$ & 13,2 & 17,1 \\
\hline $\mathrm{h}_{3}, \mathrm{MM}$ & 0,015 & 0,028 \\
\hline $\mathrm{W}, \mathrm{MKM} \mathrm{CM}{ }^{2} / \mathrm{K} \Gamma$ & 0,30 & 0,51 \\
\hline
\end{tabular}

Примітка: де $v_{a}, v_{u}, v, b_{д}, b_{u}, b-$ параметри опорної кривої; $R_{\operatorname{maxд~}}-$ максимальна висота нерівностей деталі; а - відстань між поверхнями контакту; $\mathrm{W}$ - продуктивність зрізання мікронерівностей.

ми брусками з карбіду кремнію зеленого на гливталевій зв'язці (63сM28СМ2Гл та 63с5сM2 Гл) зернистістю 28 і 50 мкм, розміри брусків $50 \times 10 \times 5$. Режими хонінгування: швидкість обертання хонінгувальної головки $\mathrm{V}=$ $=10 \mathrm{M} / \mathrm{Хв}$, питомий тиск брусків qa 10 МПа, час оброблення 30 c. Фізико-механічні характеристики деталі та інструменту: Характеристики деталі та інструменту: $\mathrm{Eg}=1,1 \times 106 \mathrm{\kappa г \textrm {c }} / \mathrm{cm}^{2} ; \mathrm{E}_{\mathrm{n}}=$ $=0,9 \times 106 \mathrm{\kappa rc} / \mathrm{cm}^{2} ; \mathrm{Mg}=0,34$. Peзультати розрахунків наведені у табл.

Дані табл., що отримані методами розрахунків, достатньо точно (похибка у межах 7-10 \%) співпадають з експериментальними результатами.

\section{Висновки}

На основі проведених досліджень необхідно зробити наступні висновки:

1. Запропонована теоретична модель для детального експериментального дослідження надтонких процесів контактної взаємодії поверхні гладкої деталі оброблення з абразивним інструментом під час виконання оздоблювально-викінчувальних операцій технологічного процесу виготовлення нових деталей тертя для поліграфічної техніки.

2. Створена система рівнянь дозволяє встановити сутність та виконати аналіз фізичних явищ, які відбуваються у поверхневих шарах деталей, що оброблю- 
ються надтонким суперфінішуванням та хонінгуванням.

3. Розроблена математична модель, що підтверджена експериментальними результатами, дозволяє цілеспрямовано призначати технологічні параметри надтонкої абразивної обробки композитних деталей тертя офсетних друкарських машин, а саме, встановлювати зусилля різання і технологічні зазори між поверхнями деталі та інструменту, що забезпечуватимуть стабільно високі параметри якості поверхні оброблюваної деталі, які $€$ передумовою високої зносостійкості і довговічності вузла тертя i поліграфічної машини у цілому.

4. Отримані результати теоретичного дослідження дозволяють розповсюдити їх для дослідження гами нових композитних матеріалів для пар тертя сучасних друкарських машин.

5. Подальші дослідження доцільно продовжити для широкого кола питань, пов'язаних із застосуванням для операцій прецизійного технологічного оброблення 3 застосуванням інструментів із синтетичних алмазів та кубічного нітриду бора.

1. Динник А. Н. Избранные труды [Текст] / А. Н. Динник А.Н.-Т. 1. Удар и сжатие упругих тел. - К. : Изд-е АН УССР, 1952. - 195 с. 2. Беляев Н. М. Местные напряжения при сжатии упругих тел [Текст] / Н. М. Беляев. В. кн. : Инженерные сооружения и строительная механика. - Л., 1924. С. 30-43. 3. Галин Л. А. Контактные задачи теории упругости [Текст] / Л. А. Галин. - М. : Гостехиздат, 1953. - 264 с. 4. Лурье А. И. Пространственные задачи теории упругости [Текст] / А. И. Лурье. - М. : Гостехиздат, 1955. - 491 с. 5. Макушин В. М. Деформация и напряженное состояние деталей в местах контакта [Текст] / В. М. Макушин. - М. : Машгиз, 1952. 211 с. 6. Мусхелишвили Н. И. Некоторые основные задачи математической теории упругости [Текст] / Н. И. Мусхелишвили. - М. : Наука, 1966. 706 с. 7. Поверхностная прочность материалов при трении [Текст] / Б. И. Костецкий, И. Г. Носовский и др. - К. : Наукова думка, 1976. - 291 с. 8. Расчеты на прочность в машиностроении [Текст] / С. Д. Пономарев, В. Л. Бидерман, К. К. Лихарев и др. - М. : Машгиз, 1958. - Т. 2. - 759 с. 9. Штаерман И. Я. Контактная задача теории упругости [Текст] / И. Я. Штаерман. - М. : Гостехиздат, 1949. - 270 с. 10. Прочность, устойчивость, колебания [Текст] : Справочник / Под ред. И. А. Биргера и Я. Г. Пановко. М. : Машиностроение, 1968. - Т. 2. - 464 с. 11. Крагельский И. В. Трение и износ в машинах [Текст] / И. В. Крагельский. - М. : Машиностроение, 1962. - 384 с. 12. Крагельский И. В. Трение и износ в машинах [Текст] / И. В. Крагельский. - М. : Машиностроение, 1968. - 480 с. 13. Крагельский И. В. Основы расчетов на трение и износ [Текст] / И. В. Крагельский, М. Н. Добычин, В. С. Комбалов. - М. : Машиностроение, 1977. - 526 с. 14. Костецкий Б. И. Износостойкость деталей машин [Текст] / Б. И. Костецкий. - М. : Машгиз, 1950. - 168 с. 15. Боуден Ф. П. Трение и смазка твердых тел [Текст] / Ф. П. Боуден, Д. У. Тейбор. - М. : Машиностроение, 1968. - 453 с. 16. Рыжов Э. В. Контактная жесткость деталей машин [Текст] / Э. В. Рыжов. - М. : Машиностроение, 1966. - 194 с. 17. Рыжов Э. В. Контактная жесткость деталей машин, обработанных инструментами из сверхтвердых материалов [Текст] : Сб. Синтетические алмазы - ключ к техническому прогрессу. - К. : Наукова думка, 1977. - Ч. 1. - С. 170-178. 18. Роїк Т. А. Композиційні підшипникові матеріали для підвищених умов ек- 
сплуатації [Текст] : Монографія / Т. А. Роїк, П. О. Киричок, А. П. Гавриш. К. : НТУУ «КП।», 2007. - 404 с. 19. Роїк Т. А. Сучасні системи технологій заготівельного виробництва в машинобудуванні [Текст] : Монографія / Т. А. Роїк, А. П. Гавриш, О. А. Гавриш. - К. : ЕКМО, 2010. - 212 с. 20. Патент України № 60522, МПК С22С33/02 (2006.01). Підшипниковий композиційний матеріал на основі інструментальної сталі / Роїк Т. А, Гавриш А. П., Киричок П. О., Гавриш О. А., Віцюк Ю. Ю., Мельник О. О. Опубл. 25.06.2011, Бюл. № 12. 21. Гавриш А. П. Вплив абразивного інструменту на шорсткість поверхонь композитних підшипників поліграфічної техніки при тонкому шліфуванні [Текст] / А. П. Гавриш, А. В. Шевчук, Т. А. Роїк та ін. // Технологія і техніка друкарства. - 2012. - № 3(37). - С. 119-127. 22. Гавриш А. П. Вибір режимів експлуатації підшипникових матеріалів з відходів швидкорізальних сталей на основі аналізу плівок тертя [Текст] / А. П. Гавриш, Т. А. Роїк, П. О. Киричок та ін. // Наукові Вісті НТУУ «КПІ». - 2011. - № 2. С. 100-107. 23. Гавриш А. П. Силове поле при тонкому абразивному шліфуванні деталей тертя з нових композиційних сплавів для друкарської техніки [Текст] / А. П. Гавриш, П. О. Киричок, Т. А. Роїк, Ю. Ю. Віцюк // Междунар. сб. науч. трудов «Прогрессивные технологии и системы машиностроения». Донецк : ДонНТУ, 2013. - Вып. 1, 2(45). - С. 35-41. 24. Гавриш А. П. Аналіз параметрів якості поверхонь підшипників ковзання з композиційних сплавів для друкарських машин при тонкому абразивному шліфуванні [Текст] / А. П. Гавриш, П. О. Киричок, Т. А. Роїк, Ю. Ю. Віцюк // Наукові Вісті НтуУ «КП।». - 2013. - № 2. - С. 52-59. 25. Гавриш А. П. Вплив режимів абразивного суперфінішування на якість поверхонь обертання композитних деталей тертя поліграфічних машин [Текст] / А. П. Гавриш, П. О. Киричок, Т. А. Роїк, Ю. Ю. Віцюк // Технологія і техніка друкарства. - 2013. № 3. - С. 54-62. 26. Маслов Е. Н. Теория шлифования материалов [Текст] / Е. Н. Маслов. - М. : Машиностроение, 1974. - 319 с. 27. Маталин А. А. Технологические методы повышения долговечности деталей машин [Текст] / А. А. Маталин. - К. : Техника, 1991. - 244 с. 28. Ящерицын П. И. Прогрессивная технология финишной обработки деталей [Текст] / П. И. Ящерицын. - Минск : Изд-во «Беларусь», 2001. - 312 с. 29. Гавриш А. П. Алмазно-абразивна обробка магнітних матеріалів [Текст] : Монографія / А. П. Гавриш, П. П. Мельничук. - Житомир : ЖДтУ, 2003. $652 \mathrm{c}$.

1. Dinnik A. N. Izbrannye trudy [Tekst] / A. N. Dinnik A.N.-T. 1. Udar i szhatie uprugih tel. - K. : Izd-e AN USSR, 1952. - 195 s. 2. Beljaev N. M. Mestnye naprjazhenija pri szhatii uprugih tel [Tekst] / N. M. Beljaev. - V. kn. : Inzhenernye sooruzhenija i stroitel'naja mehanika. - L., 1924. - S. 30-43. 3. Galin L. A. Kontaktnye zadachi teorii uprugosti [Tekst] / L. A. Galin. - M. : Gostehizdat, 1953. - 264 s. 4. Lur'e A. I. Prostranstvennye zadachi teorii uprugosti [Tekst] / A. I. Lur'e. - M. : Gostehizdat, 1955. - 491 s. 5. Makushin V. M. Deformacija i naprjazhennoe sostojanie detalej v mestah kontakta [Tekst] / V. M. Makushin. M. : Mashgiz, 1952. - 211 s. 6. Mushelishvili N. I. Nekotorye osnovnye zadachi matematicheskoj teorii uprugosti [Tekst] / N. I. Mushelishvili. - M. : Nauka, 1966. - 706 s. 7. Poverhnostnaja prochnost' materialov pri trenii [Tekst] / B. I. Kosteckij, I. G. Nosovskij i dr. - K. : Naukova dumka, 1976. - 291 s. 8. Raschety na prochnost' $v$ mashinostroenii [Tekst] / S. D. Ponomarev, V. L. Biderman, K. K. Liharev i dr. - M. : Mashgiz, 1958. - T. 2. - $759 \mathrm{~s}$. 9. Shtaerman I. Ja. Kontaktnaja zadacha teorii uprugosti [Tekst] / I. Ja. Shtaerman. - M. : Gostehizdat, 1949. - 270 s. 10. Prochnost', ustojchivost', kolebanija [Tekst] : Spravochnik / Pod red. I. A. Birgera i Ja. G. Panovko. - M. : Mashinostroenie, 1968. - T. 2. - 464 s. 11. Kragel'skij I. V. Trenie i iznos v 
mashinah [Tekst] / I. V. Kragel'skij. - M. : Mashinostroenie, 1962. - $384 \mathrm{~s}$. 12. Kragel'skij I. V. Trenie i iznos v mashinah [Tekst] / I. V. Kragel'skij. - M. : Mashinostroenie, 1968. - 480 s. 13. Kragel'skij I. V. Osnovy raschetov na trenie i iznos [Tekst] / I. V. Kragel'skij, M. N. Dobychin, V. S. Kombalov. - M. : Mashinostroenie, 1977. - 526 s. 14. Kosteckij B. I. Iznosostojkost' detalej mashin [Tekst] / B. I. Kosteckij. - M. : Mashgiz, 1950. - 168 s. 15. Bouden F. P. Trenie i smazka tverdyh tel [Tekst] / F. P. Bouden, D. U. Tejbor. - M. : Mashinostroenie, 1968. - 453 s. 16. Ryzhov Je. V. Kontaktnaja zhestkost' detalej mashin [Tekst] / Je. V. Ryzhov. - M. : Mashinostroenie, 1966. - $194 \mathrm{~s}$. 17. Ryzhov Je. V. Kontaktnaja zhestkost' detalej mashin, obrabotannyh instrumentami iz sverhtverdyh materialov [Tekst] : Sb. Sinteticheskie almazy - kljuch k tehnicheskomu progressu. - K. : Naukova dumka, 1977. - Ch. 1. S. 170-178. 18. Roik T. A. Kompozytsiini pidshypnykovi materialy dlia pidvyshchenykh umov ekspluatatsii [Tekst] : Monohrafiia / T. A. Roik, P. O. Kyrychok, A. P. Havrysh. - K. : NTUU «KPI», 2007. - 404 s. 19. Roik T. A. Suchasni systemy tekhnolohii zahotivelnoho vyrobnytstva $v$ mashynobuduvanni [Tekst] : Monohrafiia / T. A. Roik, A. P. Havrysh, O. A. Havrysh. - K. : EKMO, 2010. - 212 s. 20. Patent Ukrainy № 60522, MPK S22S33/02 (2006.01). Pidshypnykovyi kompozytsiinyi material na osnovi instrumentalnoi stali / Roik T. A, Havrysh A. P., Kyrychok P. O., Havrysh O. A., Vitsiuk lu. Iu., Melnyk O. O. Opubl. 25.06.2011, Biul. № 12. 21. Havrysh A. P. Vplyv abrazyvnoho instrumentu na shorstkist poverkhon kompozytnykh pidshypnykiv polihrafichnoi tekhniky pry tonkomu shlifuvanni [Tekst] / A. P. Havrysh, A. V. Shevchuk, T. A. Roik ta in. // Tekhnolohiia i tekhnika drukarstva. - 2012. - № 3(37). S. 119-127. 22. Havrysh A. P. Vybir rezhymiv ekspluatatsii pidshypnykovykh materialiv $\mathrm{z}$ vidkhodiv shvydkorizalnykh stalei na osnovi analizu plivok tertia [Tekst] / A. P. Havrysh, T. A. Roik, P. O. Kyrychok ta in. // Naukovi Visti NTUU «KPI». - 2011. - № 2. - S. 100-107. 23. Havrysh A. P. Sylove pole pry tonkomu abrazyvnomu shlifuvanni detalei tertia z novykh kompozytsiinykh splaviv dlia drukarskoi tekhniky [Tekst] / A. P. Havrysh, P. O. Kyrychok, T. A. Roik, lu. lu. Vitsiuk // Mezhdunar. sb. nauch. trudov «Progressivnye tehnologii i sistemy mashinostroenija». - Doneck : DonNTU, 2013. - Vyp. 1, 2(45). - S. 35-41. 24. Havrysh A. P. Analiz parametriv yakosti poverkhon pidshypnykiv kovzannia $z$ kompozytsiinykh splaviv dlia drukarskykh mashyn pry tonkomu abrazyvnomu shlifuvanni [Tekst] / A. P. Havrysh, P. O. Kyrychok, T. A. Roik, lu. lu. Vitsiuk // Naukovi Visti NTUU «KPI». - 2013. - № 2. - S. 52-59. 25. Havrysh A. P. Vplyv rezhymiv abrazyvnoho superfinishuvannia na yakist poverkhon obertannia kompozytnykh detalei tertia polihrafichnykh mashyn [Tekst] / A. P. Havrysh, P. O. Kyrychok, T. A. Roik, lu. lu. Vitsiuk // Tekhnolohiia i tekhnika drukarstva. 2013. - № 3. -- S. 54-62. 26. Maslov E. N. Teorija shlifovanija materialov [Tekst] / E. N. Maslov. - M. : Mashinostroenie, 1974. - 319 s. 27. Matalin A. A. Tehnologicheskie metody povyshenija dolgovechnosti detalej mashin [Tekst] / A. A. Matalin. - K. : Tehnika, 1991. - 244 s. 28. Jashhericyn P. I. Progressivnaja tehnologija finishnoj obrabotki detalej [Tekst] / P. I. Jashhericyn. - Minsk : Izd-vo «Belarus'», 2001. - 312 s. 29. Havrysh A. P. Almazno-abrazyvna obrobka mahnitnykh materialiv [Tekst] : Monohrafiia / A. P. Havrysh, P. P. Melnychuk. - Zhytomyr : ZhDTU, 2003. - 652 s.

\section{Рецензент - В. Ф. Морфлюк, д.т.н.,} професор, НТУУ «КПІ» 